\title{
Structural testing and design of wire arc additively manufactured
} square hollow sections

\author{
Pinelopi Kyvelou ${ }^{1}$, Cheng Huang ${ }^{2}$, Leroy Gardner ${ }^{3}$, Craig Buchanan ${ }^{4}$ \\ ${ }^{1}$ Research Associate, Dept. of Civil and Environmental Engineering, Imperial College \\ London, South Kensington Campus, London SW7 2AZ, UK. \\ Email:pinelopi.kyvelou11@imperial.ac.uk \\ ${ }^{2}$ Ph.D. Candidate, Dept. of Civil and Environmental Engineering, Imperial College London, \\ South Kensington Campus, London SW7 2AZ, UK (corresponding author). Email: \\ cheng.huang118@imperial.ac.uk \\ ${ }^{3}$ Professor, Dept. of Civil and Environmental Engineering, Imperial College London, South \\ Kensington Campus, London SW7 2AZ, UK. Email: leroy.gardner@imperial.ac.uk \\ ${ }^{4}$ Lecturer, Dept. of Civil and Environmental Engineering, Imperial College London, South \\ Kensington Campus, London SW7 2AZ, UK. Email: craig.buchanan@imperial.ac.uk
}

\section{ABSTRACT}

Wire arc additive manufacturing (WAAM) is a method of metal 3D printing that has the potential for significant impact on the construction industry due to its ability to produce large parts, with reasonable printing times and costs. There is currently however a lack of fundamental data on the performance of structural elements produced using this method of manufacture. Seeking to bridge this gap, the compressive behavior and resistance of WAAM square hollow sections (SHS) are investigated in this study. Testing reported in a previous study by the authors of sheet material produced in the same manner as the studied SHS is first summarized. The production, measurement and testing of a series of stainless steel SHS stub columns are then described. Regular cross-section profiles were chosen to isolate the influence of $3 \mathrm{D}$ printing and enable direct comparisons to be made against equivalent sections produced using traditional methods of manufacture. A range of cross-section sizes and thicknesses were considered to achieve variation in the local cross-sectional slenderness of the tested specimens, allowing the influence of local buckling to be assessed. Repeat tests enabled the variability in response between specimens to be evaluated; a total of 14 SHS stub columns of seven different local slendernesses was tested, covering all cross-section classes of AISC 370 and Eurocode 3. Advanced non-contact measurement techniques were employed to determine the as-built geometric properties, while digital image correlation measurements were used to provide detailed insight into the deformation characteristics of the test specimens. Owing to the higher geometric variability of WAAM relative to 
conventional forming processes, the tested 3D printed stub columns were found to exhibit more variable capacities between repeat specimens than is generally displayed by stainless steel SHS. Comparisons of the stub column test results with existing structural design rules highlight the need to allow for the weakening effect of the geometric undulations that are inherent to the WAAM process, in order to achieve safe-sided strength predictions.

Keywords: 3D printing; additive manufacturing; digital image correlation; experiments; laser scanning; structural engineering; stub column testing; wire arc additive manufacturing

\section{INTRODUCTION}

Additive manufacturing (AM), also referred to as 3D printing, is a fabrication process where a part is formed through the sequential deposition of layers of material, as dictated by a 3D digital model. The main advantage of this novel method of manufacturing, the use of which has already substantially spread in the aerospace, automotive and biomedical industries (Campbell et al., 2012), is the ability to fabricate parts of complex geometry without the need for specific tooling (Hague et al., 2004). According to ISO/ASTM 52900 (2015), the principal types of metal AM are sheet lamination, powder bed fusion (PBF) and directed energy deposition (DED). Wire arc additive manufacturing (WAAM) is a method of DED using welding technology, where wire feedstock is melted and selectively deposited onto a substrate plate; the deposited material subsequently solidifies and the desired component is formed layer by layer - see Figure 1 (PAS 6012, 2020). WAAM has the potential for significant impact on the construction industry since it can be used for the production of large-scale parts while allowing for high deposition rates, good structural integrity, reasonable costs and reduced waste material compared to conventional manufacturing processes (Buchanan and Gardner, 2019; Williams et al., 2015). Although other metallic AM methods can achieve higher geometrical complexity and accuracy, WAAM allows reduced lead times and manufacturing costs (Lockett et al., 2017), using mature technology and wire feedstock of low cost (Thompson et al., 2016). Finally, design freedom and printing efficiency can be further enhanced by incorporating multi-axis robotic arms and by adopting multi-direction slicing methodologies, which allow material deposition along multiple directions, thus eliminating the need for supporting structures (Ding et al., 2015; Zhang and 63 Liou, 2013).

Although WAAM is offering a revolutionary potential for the construction industry, reliable design guidance on the structural behaviour of metal 3D printed structures is required to 
enable integration of this new technology to the construction sector. Thus far, structural engineering research has been focused on structural elements printed by other AM methods (Yan et al., 2019; Chen et al., 2018; Buchanan et al., 2017; Yasa, 2011) while experimental data on WAAM structural elements are currently scarce (Laghi et al., 2019; Ji et al., 2017; Haden et al., 2017).

The world's first large-scale demonstrator of WAAM for structural applications is the stainless steel 3D printed bridge shown in Figure 2, constructed by the Dutch start-up company MX3D. The bridge has an overall mass of approximately 7.8 tonnes (of which approximately 4.6 tonnes was printed at a typical deposition rate of $0.5-2.0 \mathrm{~kg} / \mathrm{h}$ ), a span of about $10.5 \mathrm{~m}$ and an average width of about $2.5 \mathrm{~m}$ (Gardner et al., 2020). Being the first of its kind, and featuring material properties and structural behavior beyond the scope of existing design specifications, this novel structure has required extensive experimental and numerical research for its safety to be demonstrated.

A comprehensive experimental programme, comprising material (Kyvelou et al., 2020) and cross-sectional tests on tubular sections, has been conducted to support the construction and verification of the MX3D bridge, as well as to explore the potential for wider application of this technology. All tested specimens were printed by MX3D utilising the same feedstock material and printing parameters that were used for the bridge. The destructive experiments were undertaken in the Structures Laboratory in the Department of Civil and Environmental Engineering at Imperial College London while extensive non-destructive physical testing of the bridge has also been undertaken (Gardner et al., 2020).

In this paper, cross-sectional tests on 14 WAAM stub columns of square hollow section (SHS) members, printed using the same material and production parameters as the MX3D bridge, are presented. The process followed for the production, measurement and testing of the stub columns is described while the test results are analysed and discussed. Finally, comparisons are made against the strength predictions of current structural design specifications (AISC 370, 2020; EN1993-1-4, 2020) and against the performance of AM PBF (Buchanan et al., 2017) and conventionally formed austenitic (Chen et al., 2018; Yuan et al., 2014; Gardner and Nethercot, 2004; Rasmussen, 2000; Rasmussen and Hancock, 1993), ferritic (Arrayago et al., 2016; Afshan and Gardner, 2013) and duplex (Chen et al., 2018; Yuan et al., 2014; Theofanous and Gardner, 2009) stainless steel SHS. 


\section{MATERIAL TESTS}

In order to determine the stress-strain characteristics of the WAAM material, a comprehensive series of tensile coupon tests was undertaken in a previous study by Kyvelou et al. (2020); the key aspects of this study are summarized herein. Dog-bone shaped coupons were extracted from WAAM plates at $0^{\circ}, 45^{\circ}$ and $90^{\circ}$ to the printing direction, as defined in Figure 3, to investigate the material anisotropy. The influence of the geometric undulations resulting from the WAAM process on the effective material properties was assessed by testing both as-built and machined coupons; for the machined coupons, all surface undulations were removed using an end mill prior to testing. In total, 39 as-built and 12 machined coupons were tested.

A summary of the average material properties by printing direction (i.e. $0^{\circ}, 45^{\circ}$ and $90^{\circ}$ ) for the as-built and machined coupons is presented in Tables 1 and 2, respectively, where $\theta$ is the direction of testing relative to the print layer orientation as defined in Figure $3, t_{\text {nom }}$ is the nominal thickness of the coupon, $E$ is the Young's modulus, $\sigma_{0.2}$ and $\sigma_{1.0}$ are the $0.2 \%$ and $1.0 \%$ proof stresses respectively, $\sigma_{\mathrm{u}}$ is the ultimate tensile stress, $\varepsilon_{\mathrm{u}}$ is the strain at the ultimate tensile stress and $n, m_{1.0}$ and $m_{\mathrm{u}}$ are the strain hardening exponents of the two-stage RambergOsgood material model (Gardner, 2019; Arrayago et al., 2015; Gardner and Ashraf, 2006; Rasmussen, 2003; Mirambell and Real, 2000; Hill, 1944; Ramberg and Osgood, 1943). Note that the mechanical properties of the as-built material are referred to as effective (signified by 'eff' in the subscripts of the symbols) to acknowledge the influence of the undulating geometry. The results highlight the anisotropic behavior of the printed material, while the influence of the irregular geometry on the effective mechanical properties of the WAAM material was shown to be detrimental (and more prominent for loading acting perpendicular to the layer orientation). A more detailed description of the employed test setup and obtained results is provided by Kyvelou et al. (2020).

\section{STUB COLUMN TESTS}

Compression tests on WAAM SHS stub columns were conducted to investigate their compressive structural response and load carrying capacity. Simple geometries (i.e. square) were chosen deliberately for the stub column test specimens to enable the influence of the production process alone on the exhibited structural response to be isolated and to allow direct comparisons to be made against traditionally manufactured tubular sections and their corresponding design provisions. Variation in the local cross-section slenderness of the tested 
specimens was considered by adjusting the cross-sectional proportions (i.e. the outer

130 dimensions and wall thickness), allowing the influence of local buckling to be assessed, while

131 repeated tests enabled the variability in response to be evaluated; 14 SHS stub columns were

132 tested in total.

133 The adopted labelling system for the test specimens begins with the nominal cross-sectional

134 dimensions in $\mathrm{mm}$ (in the form width $\times$ depth $\times$ thickness), followed by the nominal length in

$135 \mathrm{~mm}$ and the letter ' $\mathrm{F}$ ' indicating fixed end conditions; a specimen label ending with an ' $\mathrm{R}$ ' is

136 a repeat test. Note that specimens $120 \times 120 \times 8.0-450-\mathrm{F}$ and $130 \times 130 \times 3.5-500-\mathrm{F}$ (and their

137 repeats) were chosen to be of similar proportions (i.e. similar width-to-thickness ratios) to

138 key elements of the MX3D bridge. A comparison between specimen $120 \times 120 \times 8.0-450-\mathrm{F}$ and

139 its corresponding part of the substructure of the bridge is shown in Figure 4.

$140 \quad 3.1$ Production and preparation of SHS specimens

141 The SHS specimens were manufactured by the Dutch start-up company MX3D, using their 142 proprietary multi-axis robotic WAAM technology (MX3D, 2019). The employed printer 143 comprised a 6-axis robotic arm coupled with a metal inert gas (MIG) welding machine. CAD 144 models of the specimens were drawn in Rhino 3D (2017) and sliced into finite layers that the 145 printer could trace along the cross-section slices. Then, wire feedstock, continuously supplied 146 to the printer, was melted and deposited onto a substrate plate, building up the specimen layer 147 by layer. The utilised feedstock material was Grade 308LSi austenitic stainless steel wire. 148 During the deposition process, the current was 100-140 A, the arc voltage was 18-21 V, while 149 the deposition rate was typically between 0.5 and $2.0 \mathrm{~kg} / \mathrm{h}$. For the stub columns of $3.5 \mathrm{~mm}$ 150 nominal thickness, wire of $1.0 \mathrm{~mm}$ diameter was employed with a welding speed of $15-30$ $151 \mathrm{~mm} / \mathrm{s}$ and a wire feed rate of $4-8 \mathrm{~m} / \mathrm{min}$ while for the stub columns of $8.0 \mathrm{~mm}$ nominal thickness, wire of $1.2 \mathrm{~mm}$ diameter was used with a welding speed and wire feed rate of 13 $\mathrm{mm} / \mathrm{s}$ and $5.7 \mathrm{~m} / \mathrm{min}$ respectively. Finally, the employed shield gas was $98 \%$ AR and $2 \%$

$154 \mathrm{CO}_{2}$, at a flow rate of 10-20 L/min. Printing of typical specimens is illustrated in Figure 5.

155 Following their fabrication, the stub columns were detached from their substrate plate using a 156 plasma arc cutter and then cut to specified lengths of approximately four times the outer 157 cross-section dimensions; this was chosen to be long enough to include a representative 158 distribution of residual stresses and geometric imperfections, yet short enough to prevent overall flexural buckling (Ziemian, 2010). Both ends of the stub columns were machined to be flat and parallel and the exterior surfaces were sandblasted with glass beads to remove any 
welding soot from the WAAM process. The cutting process and surface treatment of a typical specimen are shown in Figures 6(a) and 6(b) respectively.

\subsection{Geometrical measurements}

Measuring the geometry of the stub column test specimens was more challenging than usual due to the surface undulations and wall thickness variation arising as a result of the WAAM process. Hand measurements, along with a number of more sophisticated techniques $-3 D$ laser scanning, silicone casting and measurements based on Archimedes' principle - were employed to determine the as-built geometric properties of the SHS specimens. 3D laser scanning and silicone casting were finally adopted, while the hand and Archimedes' measurements served as references for comparison and verification purposes.

\subsubsection{Hand measurements}

Digital hand calliper measurements were taken to provide baseline geometric data for the examined specimens. Measurements of the SHS face widths (i.e. the outer dimensions $H_{\mathrm{h}}$ ) were taken at five locations along the length of each specimen (including the two ends), while the wall thickness $t_{\mathrm{h}}$ was recorded at three equally spaced locations on each face, at both ends (i.e. 12 measurements per end in total). Finally, separate length measurements $L_{\mathrm{h}}$ were taken along each SHS face (utilising a tape measure for the longer specimens). The average geometric properties are listed in Table 3 , where $A_{\mathrm{h}}$ is the cross-sectional area calculated using the average values of the measurements and with the inner and outer corner radii taken as equal to $1.0 t_{\mathrm{h}}$ and $1.5 t_{\mathrm{h}}$ respectively, based on hand measurements.

\subsubsection{Archimedes' principle}

182 The water displacement method, which is based on Archimedes' physical law of buoyancy

183 and is frequently employed to determine porosity in concrete elements (Ibrahim et al. 2014;

184 Park and Tia, 2004) and diffusible hydrogen in welds (Schmid and Rodabaugh, 1980), was

185 utilised for the determination of the average cross-sectional areas of the examined stub columns. Each specimen was hung using chains from weighing scales and its mass was measured both when in air $\left(m_{\mathrm{a}}\right)$ and when submerged in a water bath $\left(m_{\mathrm{w}}\right)$; the employed setup is illustrated in Figure 7(a). The mean cross-sectional area of the specimens $A_{\text {Arch, }}$ reported in Table 3, was hence determined according to Equation (1), by dividing the resulting volume $V_{\text {Arch }}$ by the member length $L_{\mathrm{h}}$ (measured as described in Section 3.2.1). In 
191 Equation (1), $m_{\mathrm{c}, \mathrm{a}}$ and $m_{\mathrm{c}, \mathrm{w}}$ are the mass of the chain in air and in water (submerged to the same depth as with the specimen hanging) respectively and $\rho_{\mathrm{w}}$ is the density of the water.

$$
A_{\text {Arch }}=\frac{V_{\text {Arch }}}{L_{\mathrm{h}}}=\frac{\left[\left(m_{\mathrm{a}}-m_{\mathrm{c}, \mathrm{a}}\right)-\left(m_{\mathrm{w}}-m_{\mathrm{c}, \mathrm{w}}\right)\right] / \rho_{\mathrm{w}}}{L_{\mathrm{h}}}
$$

193

194

195

196

197

198

199

200

201

202

203

204

205

206

207

208

209

210

211

212

213

214

215

216

217

218

219

\subsubsection{Laser scanning}

In order to obtain an accurate and detailed representation of the external and internal surfaces of all specimens prior to testing, 3D laser scanning was employed. A FARO ScanARM, capable of capturing up to 600,000 points per second to an accuracy of $0.1 \mathrm{~mm}$, was used to scan and digitally reproduce all the printed specimens. Although full scans of the outer surface of the specimens could be taken, the physical size of the head of the laser scan arm prevented direct scanning of the complete inner surface profile (allowing only direct scanning of the inner surface at the column ends) - see Figure 7(b). Hence, silicone casting was undertaken to form a scannable replica of the internal surface of the specimens.

The silicone casts were formed using SUPERSIL 25, a two-component silicone elastomer. The components were thoroughly mixed mechanically and then degassed in a vacuum chamber to remove any entrained air - see Figure 8. A central insert was placed within the specimens, as shown in Figure 9(a), prior to casting to reduce the volume of silicone required and to facilitate easier removal. Silicone release spray was also applied to the inner and outer surfaces of the specimens and inserts respectively. The prepared silicone mixture was then slowly poured in between the insert and the specimen, to avoid the introduction of air voids, which could affect the scanned silicone surface, and allowed to set for at least 24 hours. Once set, the insert was removed, allowing the silicone cast to be collapsed into the void and removed from the printed specimen - see Figure 9(b). A silicone cast adjacent to its parent SHS stub column is shown in Figure 10. Following its extraction from within the specimen, the cured silicone internal replica was laser scanned.

The outer steel and inner silicone scans of the as-built geometries were merged and converted into 3D CAD models with polygon meshes using Geomagic Wrap (2017). The CAD models were subsequently imported into Rhino 3D (2017), where contouring of the specimens was undertaken, allowing accurate determination of the cross-sectional dimensions. Processing of a typical specimen in Rhino is presented in Figure 11, where only a limited number of crosssectional contours is shown for illustration purposes. 
Special attention was given to the determination of the most suitable contour spacing $\mathrm{d} x$ along the length of the specimens in order to achieve computational efficiency and accurate determination of the geometric properties. A sensitivity study was therefore undertaken on a typical specimen and its repeat $(80 \times 80 \times 3.5-320-\mathrm{F}$ and $80 \times 80 \times 3.5-320-\mathrm{FR})$, obtaining their geometric measurements at contour spacings of $0.1 \mathrm{~mm}, 0.2 \mathrm{~mm}, 0.5 \mathrm{~mm}, 1.0 \mathrm{~mm}$ and 2.0 mm. The obtained results are presented in Figure 12, where the mean, minimum and maximum measurements of the cross-sectional area $\left(A, A_{\min }\right.$ and $A_{\max }$, respectively) determined for the different contour spacings are normalized against the equivalent values corresponding to $\mathrm{d} x=0.1 \mathrm{~mm}$. As expected, the extreme values of the measurements (i.e. $A_{\min }$ and $\left.A_{\max }\right)$ were more sensitive to the contour spacing compared to the respective mean values (i.e. $A$ ). Overall, since the measurements obtained using a spacing of $0.2 \mathrm{~mm}$ were almost identical to these obtained with a spacing of $0.1 \mathrm{~mm}$, a contour spacing of $0.2 \mathrm{~mm}$ was adopted. Note that the considered contour spacings were all below the typical WAAM deposition width $w$, shown in Figure 13, which was found to vary between about $3 \mathrm{~mm}$ and 5 $\mathrm{mm}$ for the studied specimens; a similar value of $4 \mathrm{~mm}$ was reported by Ding et al. (2014).

A summary of the geometric properties of all specimens, as obtained from the laser scans, is presented in Table 4, where $t$ and $t_{\mathrm{sd}}$ are the mean and standard deviation values of the thickness respectively, $A, A_{\max }$ and $A_{\min }$ are the mean, maximum and minimum crosssectional areas respectively, $H$ is the average face width and $r$ and $R$ are the inner and outer corner radii, obtained by means of fitting a cylinder to the scanned data of each corner region, as illustrated in Figure 14.

\subsubsection{Comparison between methods}

242 Comparisons between the geometric properties determined using the different measuring techniques are presented in Table 5. The average cross-sectional areas determined from the hand measurements $A_{\mathrm{h}}$ differ somewhat, ranging between $10 \%$ below to $15 \%$ above, from those calculated based on Archimedes' principle $A_{\text {Arch. }}$ This confirms that the use of hand measurements alone can lead to substantial errors in the determination of the geometric properties of WAAM specimens; this is because the discrete hand measurements cannot, in general, be extrapolated to the full sample. Conversely, there is very good agreement between the cross-sectional areas $A_{\text {Arch }}$ and $A$, with differences consistently below $3 \%$, providing confidence in the employed 3D laser scanning technique - see Table 5. 


\subsection{Results of geometric measurements}

252 Comparisons between the values of the mean and minimum and mean and maximum crosssectional areas, as obtained by laser scanning ( $A_{\min } / A$ and $A_{\max } / A$ respectively), are presented in Table 5, revealing the maximum geometric variation within a given specimen. Histograms showing the cross-sectional area variation within specimens are presented in Figure 15, where each cross-sectional area measurement $A_{\mathrm{i}}$ is normalized by the corresponding average cross-sectional area $A$ of each specimen. The values of the coefficient of variation (COV) of the area $V_{\mathrm{A}}$, defined as the ratio of the standard deviation of the area divided by the average area $A_{\mathrm{sd}} / A$ of each specimen, are reported in Table 5, and were found to range between 0.04 and 0.10; a similar statistical geometric measure (i.e. $t_{\mathrm{sd}} / t$ ) was used by Kyvelou et al. (2020) to predict the influence of the geometric undulations on the effective mechanical properties of WAAM sheet material.

\subsection{Local geometric imperfections}

264 Determination of the amplitudes of the local geometric imperfections, as distinct from the surface undulations associated with the individual weld layers - see Figure 16, along the length of the examined specimens was undertaken using the points located along the centreline of the outer flat faces (i.e. along one line per face) - see Figure 17. The imperfection amplitude for each face was then defined as the maximum deviation of the selected data points from a straight line fitted to the data using least squares regression. This definition of local imperfection amplitude is considered to be appropriate for evaluating the structural performance of the examined profiles and for use in subsequent numerical analyses, since it is the deviation from flatness along the longitudinal axis of structural elements that triggers and amplifies local instability phenomena (i.e. local plate buckling) and hence governs the ultimate cross-section strength. However, simply using the maximum deviation of the raw data from the reference line was deemed to be inappropriate due to the presence of some particularly prominent surface undulations and pronounced weld beads, which could result in unrealistically large imperfection amplitudes. Therefore, to eliminate the effect of these unwanted features from the data, the obtained imperfection distributions were smoothed to a $10 \mathrm{~mm}$ moving average curve, a typical example of which is shown in

280 Figure 18 . The $10 \mathrm{~mm}$ averaging interval spanned 3 to 4 weld layers and was found, by trial and error, to be suitable for removing the unwanted features, without affecting the underlying 
pronounced weld beads on one of the faces were not fully removed using the moving average approach and hence resulted in unrepresentative imperfection amplitudes; these were therefore removed manually - see Figure 19.

286 The maximum deviation of the smoothed curves from the reference line among the four faces was then taken as the local imperfection amplitude of each specimen $e_{\max }$, as reported in Table 4. The maximum measured imperfection values typically lie between about $0.5 \mathrm{~mm}$ and $2.0 \mathrm{~mm}$; these are higher than the imperfection values typically observed in conventionally formed sections (Meng and Gardner, 2020; Schafer and Pekoz, 1998) and similar to the dimensional accuracy of around $\pm 1.0 \mathrm{~mm}$ to $\pm 2.0 \mathrm{~mm}$ generally quoted for WAAM elements (Kumar et al., 2020; Li et al., 2020; Laghi et al., 2019). There was no clear link in the limited dataset between the imperfection amplitude and either the thickness or width of the examined specimens. Note that the largest imperfection amplitude was recorded for specimen $180 \times 180 \times 3.5-720$-FR; visual inspection of this specimen confirmed the lower print quality.

297 A histogram of all 56 local imperfection amplitude measurements (one measurement per section face) is presented in Figure 20, where the cumulative distribution function (CDF) is also plotted. CDF values, along with the key statistics, are given in Table 6. A CDF value, expressed as $\mathrm{P}\left(e_{\max , \mathrm{r}}<e_{\max , \mathrm{d}}\right)$, reflects the probability that the maximum geometric imperfection in a randomly selected WAAM specimen $e_{\max , \mathrm{r}}$ is less than a defined value $e_{\max , \mathrm{d}}$. The $\mathrm{P}\left(e_{\max , \mathrm{r}}<e_{\max , \mathrm{d}}\right)=0.95$ (i.e. the characteristic value of the imperfection) corresponds to $e_{\text {max,d }} \approx 3.0 \mathrm{~mm}$, indicating that a WAAM member is expected to have maximum imperfections greater than this value only $5 \%$ of the time.

\subsection{Test setup}

306 The experimental layout adopted for the compressive stub column tests is presented in Figure

307 21. The load was applied through an Instron $3500 \mathrm{kN}$ testing machine at a displacement rate 308 of $0.5 \mathrm{~mm} / \mathrm{min}$ while a self-locking spherical head was used to ensure full contact between 309 the stub column ends and end platens. Four equally spaced linear variable displacement 310 transducers (LVDTs) and four strain gauges attached to the specimens at mid-height on 311 opposite faces were used to measure the vertical deformation of the test specimens, while a 312 load cell within the testing machine measured the applied load - this setup has also been used 313 for previous SHS stub column tests (Buchanan et al., 2017; Wang et al., 2017). 
314 Owing to the undulating surface of the examined specimens, a two-component PS polyester 315 adhesive was employed as a surface precoating agent to provide a smooth surface for the 316 attachment of the strain gauges. However, this technique was deemed to provide accurate 317 measurements only up to $0.2 \%$ strain, which corresponds to strains substantially lower than 318 those reached during testing. Furthermore, the localised nature of strain gauge readings 319 renders them less representative of the overall structural response in specimens with 320 undulating surfaces; hence, the use of strain gauges was omitted for most of the conducted 321 tests. It should be also mentioned that the testing machine size and the length of specimens $180 \times 180 \times 3.5-720-\mathrm{F}$ and $180 \times 180 \times 3.5-720-\mathrm{FR}$ rendered the use of the self-locking spherical head infeasible; cement grout was used at the top of these specimens instead to ensure full contact between the stub column ends and the loading platen.

Axial load, strain gauge (when used) and LVDT measurements were recorded at a frequency of $2 \mathrm{~Hz}$ using an in-house developed data logger. A two camera LaVision DIC system was also used, acquiring images at a frequency of $0.2 \mathrm{~Hz}$, allowing surface deformations and strain fields to be accurately recorded for one of the flat faces of the specimen; the applied force was also recorded through an analogue to digital converter. The acquired images were processed in the software DaVis (LaVision, 2017). Vertical displacements adjacent to the top and bottom end platens were calculated, exported and subtracted to determine the true end shortening response of the stub columns. The surface deformation field of a typical WAAM specimen at the peak load is presented in Figure 22(a) while the equivalent field for a PBF SHS specimen of similar slenderness (Buchanan et al., 2017) is shown in Figure 22(b). It can be observed that the deformation field of the WAAM specimen is less regular than for the PBF specimen, especially in terms of out-of-plane deformations. This is attributed to the more variable geometry of the as-built WAAM specimens, particularly the variations in thickness and the surface undulations.

\subsection{Test results}

340 Two alternative methods were initially adopted for the determination of the load-end

341 shortening curves: (i) using the LVDT and strain gauge data, accounting for the deformation 342 of the end platens (Meng and Gardner, 2020; Zhao et al., 2015; Gardner et al., 2016; Centre 343 for Advanced Structural Engineering, 1990), and (ii) using the DIC data, by subtracting the vertical deformations recorded at the stub column ends. Typical comparisons between loadend shortening curves derived according to these two different approaches are shown in 
346 Figure 23, where it is apparent that the curves yielded by the two different methods are 347 almost identical. Hence, only the DIC derived results are reported herein since they are 348 deemed to be generally more accurate since the measurements are made directly on the 349 specimens.

350 The load-end shortening curves of all specimens are presented in Figure 24, while a summary of the obtained results is given in Table 7, where $N_{\mathrm{u}}$ is the ultimate axial load and $\delta_{\mathrm{u}}$ is the column end shortening at $N_{\mathrm{u}}$ as calculated from the DIC data. The deformed shapes of the stub columns, shown in Figure 25, although akin to the classical 'in-out' local buckling, were clearly influenced by the initial imperfections and surface undulations inherent to the WAAM process.

Some variation in structural behavior between repeat specimens was observed, with differences in ultimate capacity up to $18 \%$, reflecting the greater geometric variability associated with WAAM cross-sections relative to conventional sections. In Figure 26(a), the normalized axial resistance $N_{\mathrm{u}} / A \sigma_{0.2, \text { eff }}$ of the tested specimens is plotted against the local slenderness $c /(t \varepsilon)$, in order to capture the general trend of decreasing capacity with increasing local slenderness. In Figure 26(a), $c$ is the mean flat width of the faces of the SHS, $t$ is the mean thickness and $\varepsilon=\sqrt{\left(235 / \sigma_{0.2}\right) /(E / 210000)}$ (EN 1993-1-4, 2006). In Figure 26(b), the normalized axial resistance $N_{\mathrm{u}} / A \sigma_{0.2 \text {,eff }}$ of each specimen is itself normalized by the general $N_{\mathrm{u}} / A \sigma_{0.2, \text { eff }}$ versus $c / t \varepsilon$ linear regression trend for all tested specimens, the expression for which is denoted $\rho_{\text {linear }}$ and given in Figure 26(a), and plotted against the local imperfection amplitude $e_{\max }$ (as defined in Section 3.3) normalized by the average thickness $t$. It is clear from the results that the relative structural performance of the WAAM specimens degrades with increasing $e_{\max } / t$ values, and that geometric imperfections are the key cause of variation in structural behavior between the repeat tests.

370 Analysis of the geometric data from the laser scans revealed a general correlation between the location of failure (i.e. local buckling) in the specimens and the regions containing the most prominent thickness reductions and geometric imperfections. In Figure 27, the average wall thickness $t$ and imperfection amplitude $e$ (as defined in Section 3.3) of each cross-section are plotted against the specimen length for two typical specimens (one for each nominal thickness). It can be observed that local buckling is triggered in areas where high values of imperfections and low values of thickness coincide. 


\section{STRUCTURAL DESIGN OF WAAM ELEMENTS}

378 Before broader application of metal 3D printing in the construction sector is possible, further research and greater standardisation is needed. In this section, the performance of the examined WAAM SHS specimens is initially compared against the response of conventionally manufactured SHS, and, subsequently, against strength predictions yielded by design standards of current practice, in order to assess their suitability for the structural design of WAAM SHS.

4.1 Comparisons with existing tests data on conventionally manufactured stainless steel SHS

386

The structural performance of the tested WAAM specimens is compared with that of AM PBF (Buchanan et al., 2017) and conventionally formed austenitic (Chen et al., 2018; Yuan et al., 2014; Gardner and Nethercot, 2004; Rasmussen, 2000; Rasmussen and Hancock, 1993), ferritic (Arrayago et al., 2016; Afshan and Gardner, 2013) and duplex (Chen et al., 2018; Yuan et al., 2014; Theofanous and Gardner, 2009) stainless steel SHS in this subsection. A graphical illustration is presented in Figure 28, where the normalized axial resistance $N_{\mathrm{u}} / A \sigma_{0.2}$ of the tested specimens is plotted against the local slenderness $c /(t \varepsilon)$, where $c$ is the mean flat width of the faces of the SHS, $t$ is the mean thickness and $\varepsilon=$ $\sqrt{\left(235 / \sigma_{0.2}\right) /(E / 210000)}(\mathrm{EN} 1993-1-4,2006)$. Note that, although in the new version of EN 1993-1-4 (2020) the calculation of $\varepsilon$ has been simplified by omitting the E/210000 ratio, it has been retained herein because of the significant deviation of the Young's modulus $E$ of the WAAM material from that of traditionally produced material.

398 Comparisons are shown based on both the machined and effective material properties. It is 399 clear that, when the underlying material properties of the machined coupons are used, the cross-sections under-perform relative to current design provisions. However, when the effective material properties are used, the weakening effect of the geometric undulations, caused by local thickness variations and eccentricities associated with the individual weld layers, is normalized out, and the obtained test results fall within the range of conventionally produced SHS stainless steel stub columns.

\subsection{Comparisons with AISC 370}

406 In this sub-section, the ultimate test capacities of the WAAM stub columns are compared to 407 the strength predictions determined according to AISC 370 (2020). Two different sets of 
material properties were utilised in the design equations: (1) the material properties ( $E$ and $\sigma_{0.2}$ ) from the machined coupons in the $90^{\circ}$ direction, as reported in Table 2 and (2) the effective material properties ( $E_{\text {eff }}$ and $\sigma_{0.2, \text { eff }}$ ) from the as-built coupons in the $90^{\circ}$ direction for both nominal material thicknesses (i.e. $3.5 \mathrm{~mm}$ and $8.0 \mathrm{~mm}$ ), as reported in Table 1. Note that the influence of the geometric undulations associated with WAAM inherently features in the effective material properties determined from the tensile coupon tests performed on the asbuilt material. The capacity predictions derived using the two different sets of material properties are denoted $N_{\mathrm{u}, \mathrm{AISC}, \mathrm{m}}$ and $N_{\mathrm{u}, \mathrm{AISC} \text {,eff }}$ respectively. The mean cross-sectional dimensions, as determined from the laser scans, were used in all design calculations and all safety factors were set to unity.

Comparisons between the test results and AISC 370 strength predictions are presented in Figure 29 and listed in Table 8. Note that, although the reduction factor accounting for local buckling is used in the design equations to reduce only the flat widths of the SHS faces (and not the gross cross-sectional area), in Figure 29, for illustration purposes, the AISC 370 reduction factor function has been directly plotted. It can be observed that use of the material properties obtained from the machined coupons leads to consistent overpredictions of the load-carrying capacities of the examined cross-sections (with $N_{\mathrm{u}} / N_{\mathrm{u}, \mathrm{AISC}, \mathrm{m}}=0.85$ on average), while use of the effective material properties leads to more reasonable and safe-sided resistance predictions (with $N_{\mathrm{u}} / N_{\mathrm{u}, \mathrm{AISC} \text {,eff }}=1.12$ on average). Hence, it is clear that account of the weakening effect of geometric undulations should be taken (for example through the use of effective material properties as adopted herein or through an alternative reduced thickness approach) to achieve suitable strength predictions using the AISC 370 resistance function, but further data and reliability analyses are required before a suitable safety factor could be derived.

\subsection{Comparisons with EN 1993-1-4}

In this sub-section, the ultimate test capacities of the WAAM stub columns are compared to the resistance predictions determined according to EN 1993-1-4 (2020). The comparisons are illustrated in Figure 30 and are presented in Table 9, together with the compressive crosssection classes. As in Section 4.2, use of the material properties from both the machined and as-built coupons for the $90^{\circ}$ direction has been assessed in the EN 1993-1-4 resistance

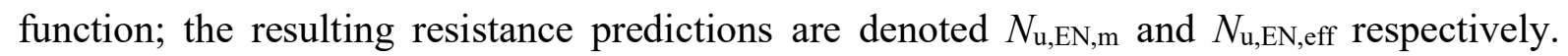
Note that effective cross-sectional properties have been calculated for Class 4 sections in line 
with EN 1993-1-4 (2020) and EN 1993-1-5 (2006) to account for the loss of effectiveness

441 due to local buckling while $\varepsilon$ was calculated as explained in Section 4.1 (i.e. $\varepsilon=$ $\left.442 \sqrt{\left(235 / \sigma_{0.2}\right) /(E / 210000)}\right)$. Also, as for the AISC 370 comparisons, although the reduction 443 factor accounting for local buckling $\rho$ is only used to reduce the flat widths of the SHS faces 444 (and not the gross cross-sectional area), in Figure 30, for illustration purposes, the EN 1993445 1-4 reduction factor function has been directly plotted.

446 It is clear that, when the underlying material properties of the machined coupons are used, the 447 load-carrying capacities of the examined cross-sections are generally overpredicted (with $448 N_{\mathrm{u}} / N_{\mathrm{u}, \mathrm{EN}, \mathrm{m}}=0.85$ on average). Conversely, when the effective material properties of the 449 undulating coupons are employed, more reasonable resistance predictions are achieved (with $450 N_{\mathrm{u}} / N_{\mathrm{u}, \mathrm{EN} \text {,eff }}=1.13$ on average). Hence, as for AISC 370, provided the weakening effect of the 451 undulations inherent in the as-built geometry is considered (through the use of effective 452 mechanical properties in the present study), adequate resistance predictions for WAAM SHS 453 in compression are achieved using the existing EN 1993-1-4 (2020) design equations. Again, 454 further data and reliability analyses are required before a suitable safety factor could be 455 derived.

\section{$456 \quad 4.4$ Comparisons with the continuous strength method}

457 The continuous strength method (CSM) (Arrayago et al., 2020; Afshan and Gardner, 2013; 458 Gardner et al., 2011) has been also used to predict the cross-sectional resistances of the tested 459 WAAM specimens. The CSM, which has been recently included in both AISC 370 (2020) 460 and EN 1993-1-4 (2020), is a deformation-based design approach that accounts for the 461 beneficial influence of strain hardening. The CSM capacities predicted using the material 462 properties of the machined and as-built coupons are denoted $N_{\mathrm{u}, \mathrm{csm}, \mathrm{m}}$ and $N_{\mathrm{u}, \mathrm{csm} \text {,eff }}$ 463 respectively. Normalized CSM resistance predictions are provided in Table 10 and illustrated 464 in Figure 31 (where the CSM prediction curve has been plotted using the effective material 465 properties of the $3.5 \mathrm{~mm}$ specimens), with $N_{\mathrm{u}} / N_{\mathrm{u}, \mathrm{csm}, \mathrm{m}}=0.76$ and $N_{\mathrm{u}} / N_{\mathrm{u}, \mathrm{csm}, \text { eff }}=1.00$ on 466 average. The CSM resistance predictions are accurate when the effective material properties 467 of the as-built coupons are employed, but may, nonetheless, require recalibration for 468 application to WAAM structural elements in order to ensure that the required level of 469 reliability is achieved. 


\section{CONCLUSIONS}

471 An experimental study into the material and cross-sectional properties of WAAM stainless

472 steel structural elements has been presented. The research was carried out to gain insight into 473 the structural behavior of WAAM stainless steel members and, also, to complement the 474 safety verification of the world's first metal 3D printed bridge (Gardner et al., 2020).

475 Compression tests on a total of 14 SHS stub columns, covering a wide range of local 476 slendernesses, were performed. Sophisticated non-contact measurement techniques were 477 employed to determine the as-built geometric properties of the specimens, featuring 3D laser 478 scanning, silicone casting and measurements based on Archimedes' principle, while digital 479 image correlation measurements were used to provide detailed insight into the deformation 480 characteristics of the test specimens. It was found that the WAAM stub columns exhibited 481 more variable capacities between repeat specimens than generally displayed by 482 conventionally formed stainless steel SHS and this was demonstrated to relate principally to 483 the variation in local geometric imperfections.

484 The test results were compared with capacity predictions obtained using the AISC 370, EN 485 1993-1-4 and CSM resistance functions with mechanical properties determined from tensile 486 tests on both machined and as-built WAAM coupons, with the latter including the weakening 487 effect of the undulating geometry inherent to the WAAM process. Use of the machined 488 material properties generally resulted in unconservative capacity predictions, while this was 489 remedied through the use of the effective mechanical properties of the as-built coupons. 490 Further test data and reliability analyses are required for the determination of suitable safety 491 factors for the design of cross-sections produced by wire arc additive manufacturing.

\section{DATA AVAILABILITY STATEMENT}

493 Some or all data, models, or code that support the findings of this study are available from the 494 corresponding author upon reasonable request.

\section{ACKNOWLEDGEMENTS}

496 This experimental programme was possible thanks to funding and support from the Data 497 Centric Engineering programme at the Alan Turing Institute (ATI), funded by the Lloyd's 498 Register Foundation. This research also benefitted from EPSRC funding under grant number $499 \mathrm{EP} / \mathrm{R} 010161 / 1$ and from the UKCRIC Coordination Node EPSRC grant under $500 \mathrm{EP} / \mathrm{R} 017727 / 1$. The authors would also like to acknowledge the contributions of William 

the Department of Civil and Environmental Engineering and of Ingrid Logan and Saadiqah

504 Rahman from the Dyson School of Design Engineering at Imperial College London in the conducted experimental programme.

\section{REFERENCES}

507 3D Systems (2017) Geomagic Wrap 2017 (Version 2017.0.2:64) [Software] 2017 3D 508 Systems, Incorporated and its licensors.

509 Afshan, S. and Gardner, L. (2013) Experimental Study of Cold-Formed Ferritic Stainless 510 Steel Hollow Sections. Journal of Structural Engineering, 139 (5), 717-728.

511 Afshan, S. and Gardner, L. (2013) The continuous strength method for structural stainless 512 steel design. Thin-Walled Structures, 68, 42-49.

513 AISC 370 (2020) Specification for Structural Stainless Steel Buildings. Chicago, Illinois, 514 American Institute of Steel Construction.

515 Arrayago, I., Real, E. and Gardner, L. (2015) Description of stress-strain curves for stainless 516 steel alloys. Materials and Design, 87, 540-552.

517 Arrayago, I., Real, E. and Mirambell, E. (2016) Experimental study on ferritic stainless steel 518 RHS and SHS beam-columns. Thin-Walled Structures, 100, 93-104.

519 Arrayago, I., Real, E., Mirambell, E. and Gardner, L. (2020) The Continuous Strength 520 Method for the design of stainless steel hollow section columns. Thin-Walled Structures, 154, 521106825.

522 Buchanan, C. and Gardner, L. (2019) Metal 3D printing in construction: a review of methods, 523 research, applications, opportunities and challenges. Engineering Structures, 180, 332-348.

524 Buchanan, C., Matilainen, V.P., Salminen, A. and Gardner, L. (2017) Structural performance 525 of additive manufactured metallic material and cross-sections. Journal of Constructional 526 Steel Research, 136, 35-48.

527 Campbell, I., Bourell, D. and Gibson I. (2012). Additive Manufacturing: rapid prototyping 528 comes of age. Rapid Prototyping Journal, 18 (4), 255-258.

529 Centre for Advanced Structural Engineering (1990) Compression tests of stainless steel 530 tubular columns. Investigation Report S770. University of Sydney, Australia.

531 Chen, J., Huang, Y. and Young, B. (2019) Design of austenitic and duplex stainless steel SHS 532 and RHS beam-columns. Journal of Constructional Steel Research, 152, 143-153. 
533 Chen, M.T., Yan, J.J., Quach, W.M., Yan, M. and Young, B. (2018) Additive Manufactured 534 High Strength Steel Tubular Sections. In: Proceedings of the $8^{\text {th }}$ International Conference on 535 Thin-Walled Structures (ICTWS): 1-24. 24-27 July, Lisbon, Portugal.

536 Ding, D. H., Pan, Z. X., Dominic, C. and Li, H. J. (2014) Process planning strategy for wire and arc additive manufacturing. International Conference on Robotic Welding, Intelligence and Automation. Springer, 437-450.

EN 1993-1-4 (2020) Eurocode 3: Design of Steel Structures - Part 1-4: General Rules -

540 Supplementary Rules for Stainless Steels. Brussels, European Committee for Standardization 541 (CEN).

542 EN 1993-1-4 (2006) Eurocode 3: Design of Steel Structures - Part 1-4: General Rules 543 Supplementary Rules for Stainless Steels. Brussels, European Committee for Standardization 544 (CEN).

545 EN 1993-1-5 (2006) Eurocode 3: Design of Steel Structures - Part 1-5: Plated structural elements. Brussels, European Committee for Standardization (CEN).

EN ISO 6892- 1 (2016) Metallic materials - Tensile testing - Part 1: Method of test at room temperature. Brussels, European Committee for Standardization (CEN).

549 Gardner, L. (2019) Stability and design of stainless steel structures - Review and outlook. Thin-Walled Structures, 141, 208-216.

551 Gardner, L. and Ashraf, M. (2006) Structural design for non-linear metallic materials. Engineering Structures, 28 (6), 926-934.

553 Gardner, L., Bu, Y. and Theofanous, M. (2016) Laser-welded stainless steel I-sections: 554 Residual stress measurements and column buckling tests. Engineering Structures, 127, 536555548 .

556 Gardner, L., Kyvelou P., Herbert, G. and Buchanan, C. (2020) Testing and initial verification 557 of the world's first metal 3D printed bridge. Journal of Constructional Steel Research, 172, 558106233.

559 Gardner, L. and Nethercot, D.A. (2004) Experiments on stainless steel hollow sections - part 560 1: material and cross-sectional behaviour. Journal of Constructional Steel Research, 60 (9), 561 1291-1318.

562 Gardner, L., Wang, F. and Liew, A. (2011) Influence of strain hardening on the behavior and 563 design of steel structures. International Journal of Structural Stability and Dynamics, 11 (5), 564 855-875.

565 Haden, C., Zeng, G., Carter III, F. M., Ruhl, C., Krick, B. and Harlow, D. (2017). Wire and 566 arc additive manufactured steel: tensile and wear properties. Additive Manufacturing, 16, $567 \quad 115-123$.

568 Hague, R., Mansour, S. and Saleh, N. (2004) Material and design considerations for rapid 569 manufacturing. International Journal of Production Research, 42 (22), 4691-4708. 
570 Hill, H. (1944) Determination of stress-strain relations from the offset yield strength values.

571 Technical Note No. 927, National Advisory Committee for Aeronautics. Washington, D.C.,

572 USA.

573 Ibrahim, A., Mahmoud, E., Yamin, M. and Patibandla, V.C. (2014) Experimental study on

574 Portland cement pervious concrete mechanical and hydrological properties. Construction and

575 Building Materials, 50, 524-529.

576 ISO/ASTM 52900 (2015) Additive Manufacturing - General Principles - Terminology.

577 ASTM International, West Conshohocken, PA.

578 Ji, L., Lu, J., Liu, C., Jing, C., Fan, H. and Ma, S. (2017) Microstructure and mechanical

579 properties of 3041 steel fabricated by arc additive manufacturing. MATEC Web of

580 Conferences, 128 (EDP Sciences), 03006.

581 Kumar, P., Jain, N.K. and Sawant, M.S. (2020) Modeling of dimensions and investigations

582 on geometrical deviations of metallic components manufactured by $\mu$-plasma transferred arc

583 additive manufacturing process. The International Journal of Advanced Manufacturing

584 Technology, 7-8 (107), 3155-3168.

585 Kyvelou, P., Slack, H., Daskalaki Mountanou, D., Wadee, M.A., Britton, T.B., Buchanan, C. 586 and Gardner, L. (2020) Mechanical and microstructural testing of WAAM sheet material. 587 Materials and Design, 192, 108675.

588 Laghi, V., Palermo, M., Gasparini, G., Girelli, V. and Trombetti, T. (2019) Experimental 589 results for structural design of Wire-and-Arc Additive Manufactured stainless steel members.

590 Journal of Constructional Steel Research. [In press]

591 LaVision (2017) DaVis (Version 8.4.0) [Software] La Vision GmbH.

592 Lockett, H., Ding, J., Williams, S. and Martina, F. (2017) Design for Wire + Arc Additive 593 Manufacture: design rules and build orientation selection. Journal for Engineering Design, 59428 (7-9), 568-598.

595 Li, Y., Li, X., Zhang, G., Horváth, I. and Han, Q. (2020) Interlayer closed-loop control of 596 forming geometries for wire and arc additive manufacturing based on fuzzy-logic inference. 597 Journal of Manufacturing Processes. [In press]

598 Meng, X. and Gardner, L. (2020) Testing of hot-finished high strength steel SHS and RHS 599 under combined compression and bending. Thin-Walled Structures, 148, 106262.

600 Mirambell, E. and Real, E. (2000) On the calculation of deflections in structural stainless 601 steel beams: an experimental and numerical investigation. Journal of Constructional Steel 602 Research, 54 (1), 109-133.

603 MX3D (2019) About - MX3D. [online] Available from: https://mx3d.com/about-2/ 604 [Accessed 18 Oct. 2019]

605 Park, S.B. and Tia, M. (2004) An experimental study on the water-purification properties of 606 porous concrete. Cement and Concrete Research, 34, 177-184. 
609 Ramberg, W. and Osgood, W.R. (1943) Description of stress-strain curves by three 610 parameters. Technical Note No. 902, National Advisory Committee for Aeronautics. 611 Washington, D.C., USA.

612 Rasmussen, K. J. R. (2003) Full-range stress-strain curves for stainless steel alloys. Journal 613 of Constructional Steel Research, 59 (1), 47-61.

614 Rasmussen, K.J.R. (2000) Recent research on stainless steel tubular structures. Journal of 615 Constructional Steel Research, 54 (1), 75-88.

616 Rasmussen, K.J.R. and Hancock, G.J. (1993) Design of cold-formed stainless steel tubular 617 members. I: columns. Journal of Structural Engineering. ASCE, 119 (8), 2349-2367.

618 Rhino 3D. (2017) Rhino 3D computer-aided design software (Version 5 SR14 64-bit) 619 [Software] Robert McNeel \& Associates.

620 Ryan, E. M. (2019) On wire and arc additive manufacture of aluminium. $\mathrm{PhD}$ thesis. 621 University of Surrey, UK.

622

623

624

625

626

627

628

629

630

631

632

633

634

635

636

637

638

639

640

641

642

Schafer, B.W. and Pekoz, T. (1998) Computational modeling of cold-formed steel: characterizing geometric imperfections and residual stresses. Journal of Constructional Steel Research, 47, 193-210.

Schmid, G.C. and Rodabaugh, R.D. (1980) Water displacement method for measuring diffusible hydrogen in welds. Welding Journal, 59 (8), 217-225.

Theofanous, M. and Gardner, L. (2009) Testing and numerical modelling of lean duplex stainless steel hollow section columns. Engineering Structures, 31, 3047-3058.

Thompson, M.K., Moroni, G., Vaneker, T., Fadel, G., Campbell, R.I., Gibson, I., Bernard, A., Schulz, J., Graf, P., Ahuja, B. and Martina, F. (2016) Design for Additive Manufacturing: Trends, opportunities, considerations, and constraints. CIRP Annals - Manufacturing Technology, 65 (2), 737-760.

Wang, J., Afshan, S., Schillo, N., Theofanous, M., Feldmann, M. and Gardner, L. (2017) Material properties and compressive local buckling response of high strength steel square and rectangular hollow sections. Engineering Structures, 130, 297-315.

Williams, S.W., Martina, F., Addison, A.C., Ding, J., Pardal, G. and Colegrove, P.A. (2015) Wire + Arc Additive Manufacturing. Materials Science and Technology, 32 (7), 641-647.

Yan, J.-J., Chen, M.-T., Quach, W.-M., Yan, M. and Young, B. (2019) Mechanical properties and cross-sectional behavior of additively manufactured high strength steel tubular sections. Thin-Walled Structures, 144, 106158.

Yasa, E. and Kruth, J-P. (2011) Microstructural investigation of Selective Laser Melting 316L stainless steel parts exposed to laser re-melting. Procedia Engineering, 19, 389-395. 
643 Yuan, H.X., Wang, Y.Q., Shi, Y.J. and Gardner, L. (2014) Stub column tests on stainless 644 steel built-up sections. Thin-Walled Structures, 83, 103-114.

645 Zhang, J. and Liou, F.W. (2013) Multi-Axis Planning of a Hybrid Material Deposition and 646 Removal Combined Process. Journal of Machinery Manufacturing and Automation, 2 (3), $647 \quad 46-57$.

648 Zhao, O., Rossi, B., Gardner, L. and Young, B. (2015) Behaviour of structural stainless steel 649 cross-sections under combined loading - Part I: Experimental study. Engineering Structures, $65089,236-246$.

651 Ziemian, R.D. (2010) Guide to Stability Design Criteria for Metal Structures. 6th edition. 652 New York, John Wiley \& Sons, Inc.

653

654

\section{TABLES}

655 656

657

\begin{tabular}{cccccccccc}
\hline $\begin{array}{c}t_{\text {nom }} \\
(\mathrm{mm})\end{array}$ & $\begin{array}{c}\theta \\
\left(^{\circ}\right)\end{array}$ & $\begin{array}{c}E_{\text {eff }} \\
(\mathrm{MPa})\end{array}$ & $\begin{array}{c}\sigma_{0.2, \text { eff }} \\
(\mathrm{MPa})\end{array}$ & $\begin{array}{c}\sigma_{1.0, \text { eff }} \\
(\mathrm{MPa})\end{array}$ & $\begin{array}{c}\sigma_{\mathrm{u}, \text { eff }} \\
(\mathrm{MPa})\end{array}$ & $\varepsilon_{\mathrm{u}, \text { eff }}$ & $n_{\text {eff }}$ & $m_{1.0, \text { eff }}$ & $m_{\mathrm{u}, \text { eff }}$ \\
\hline \multirow{3}{*}{3.5} & 0 & 135900 & 333 & 362 & 553 & 0.273 & 15.5 & 1.8 & 2.2 \\
& 45 & 192600 & 344 & 391 & 570 & 0.255 & 9.4 & 2.4 & 2.3 \\
& 90 & 90200 & 261 & 319 & 448 & 0.119 & 6.5 & 2.5 & 2.6 \\
\hline \multirow{3}{*}{8.0} & 0 & 137100 & 325 & 349 & 535 & 0.325 & 22.9 & 1.8 & 2.4 \\
& 45 & 201200 & 351 & 391 & 559 & 0.255 & 11.5 & 2.3 & 2.3 \\
& 90 & 109100 & 271 & 326 & 423 & 0.103 & 5.5 & 2.6 & 2.5 \\
\hline
\end{tabular}

658

659

660

661 662

Table 2: Average material properties of machined coupons by direction of testing relative to the print layer orientation (Kyvelou et al., 2020)

663

\begin{tabular}{ccccccccc}
\hline$\theta\left(^{\circ}\right)$ & $\begin{array}{c}E \\
(\mathrm{MPa})\end{array}$ & $\begin{array}{c}\sigma_{0.2} \\
(\mathrm{MPa})\end{array}$ & $\begin{array}{c}\sigma_{1.0} \\
(\mathrm{MPa})\end{array}$ & $\begin{array}{c}\sigma_{\mathrm{u}} \\
(\mathrm{MPa})\end{array}$ & $\varepsilon_{\mathrm{u}}$ & $n$ & $m_{1.0}$ & $m_{\mathrm{u}}$ \\
\hline 0 & 143300 & 356 & 382 & 575 & 0.307 & 15.8 & 1.7 & 2.4 \\
45 & 219500 & 407 & 437 & 626 & 0.364 & 13.6 & 2.0 & 2.4 \\
90 & 139600 & 338 & 381 & 554 & 0.297 & 6.8 & 2.3 & 2.7 \\
\hline
\end{tabular}

664

665

666 
667 Table 3: Summary of the average hand measured geometric properties of the SHS specimens

\begin{tabular}{lccccc}
\hline Specimen ID & $\begin{array}{c}L_{\mathrm{h}} \\
(\mathrm{mm})\end{array}$ & $\begin{array}{c}H_{\mathrm{h}} \\
(\mathrm{mm})\end{array}$ & $\begin{array}{c}t_{\mathrm{h}} \\
(\mathrm{mm})\end{array}$ & $\begin{array}{c}A_{\mathrm{h}} \\
\left(\mathrm{mm}^{2}\right)\end{array}$ & $\begin{array}{c}A_{\text {Arch }} \\
\left(\mathrm{mm}^{2}\right)\end{array}$ \\
\hline $60 \times 60 \times 3.5-240-\mathrm{F}$ & 240.1 & 59.7 & 3.91 & 857.1 & 888.3 \\
$60 \times 60 \times 3.5-240-\mathrm{FR}$ & 240.3 & 60.0 & 3.82 & 841.8 & 838.8 \\
$80 \times 80 \times 3.5-320-\mathrm{F}$ & 320.4 & 80.0 & 3.86 & 1160.5 & 1191.9 \\
$80 \times 80 \times 3.5-320-\mathrm{FR}$ & 320.0 & 79.9 & 3.80 & 1140.9 & 1153.4 \\
$100 \times 100 \times 3.5-400-\mathrm{F}$ & 400.4 & 100.0 & 4.31 & 1627.8 & 1516.8 \\
$100 \times 100 \times 3.5-400-\mathrm{FR}$ & 409.3 & 100.0 & 4.39 & 1657.4 & 1499.2 \\
$120 \times 120 \times 8.0-450-\mathrm{F}$ & 475.4 & 119.2 & 7.23 & 3181.7 & 2876.5 \\
$120 \times 120 \times 8.0-450-\mathrm{FR}$ & 450.9 & 119.1 & 7.04 & 3101.8 & 2700.9 \\
$130 \times 130 \times 3.5-500-\mathrm{F}$ & 501.6 & 131.0 & 3.96 & 1994.1 & 1840.9 \\
$130 \times 130 \times 3.5-500-\mathrm{FR}$ & 487.5 & 130.6 & 4.35 & 2176.6 & 1829.1 \\
$150 \times 150 \times 3.5-600-\mathrm{F}$ & 600.0 & 149.6 & 3.88 & 2247.8 & 2285.4 \\
$150 \times 150 \times 3.5-600-\mathrm{FR}$ & 599.5 & 149.8 & 3.98 & 2304.7 & 2271.2 \\
$180 \times 180 \times 3.5-720-\mathrm{F}$ & 720.0 & 179.4 & 3.96 & 2761.0 & 2765.3 \\
$180 \times 180 \times 3.5-720-\mathrm{FR}$ & 720.3 & 179.1 & 3.59 & 2503.8 & 2790.1 \\
\hline
\end{tabular}

668

669

670

671

672 Table 4: Summary of the average geometric properties of the SHS specimens as determined by 673 the laser scans and by measurements based on Archimedes' principle

\begin{tabular}{lcccccccc}
\hline Specimen ID & $\begin{array}{c}H \\
(\mathrm{~mm})\end{array}$ & $\begin{array}{c}r \\
(\mathrm{~mm})\end{array}$ & $\begin{array}{c}R \\
(\mathrm{~mm})\end{array}$ & $\begin{array}{c}t \\
(\mathrm{~mm})\end{array}$ & $\begin{array}{c}A \\
\left(\mathrm{~mm}^{2}\right)\end{array}$ & $\begin{array}{c}A_{\max } \\
\left(\mathrm{mm}^{2}\right)\end{array}$ & $\begin{array}{c}A_{\min } \\
\left(\mathrm{mm}^{2}\right)\end{array}$ & $\begin{array}{c}e_{\max } \\
(\mathrm{mm})\end{array}$ \\
\hline $60 \times 60 \times 3.5-240-\mathrm{F}$ & 60.0 & 4.48 & 7.15 & 4.11 & 914.8 & 1116.0 & 795.1 & 1.41 \\
$60 \times 60 \times 3.5-240-\mathrm{FR}$ & 60.0 & 4.76 & 7.19 & 3.85 & 843.6 & 969.2 & 750.6 & 1.39 \\
$80 \times 80 \times 3.5-320-\mathrm{F}$ & 79.9 & 4.46 & 7.11 & 4.05 & 1227.4 & 1544.6 & 1069.0 & 1.65 \\
$80 \times 80 \times 3.5-320-\mathrm{FR}$ & 80.0 & 4.49 & 7.15 & 3.91 & 1182.2 & 1332.6 & 1052.5 & 2.05 \\
$100 \times 100 \times 3.5-400-\mathrm{F}$ & 100.0 & 4.32 & 6.54 & 3.99 & 1496.7 & 1703.2 & 1372.2 & 0.62 \\
$100 \times 100 \times 3.5-400-\mathrm{FR}$ & 99.9 & 4.29 & 6.79 & 3.99 & 1520.2 & 1699.0 & 1355.3 & 0.72 \\
$120 \times 120 \times 8.0-450-\mathrm{F}$ & 118.0 & 5.60 & 8.11 & 6.53 & 2894.2 & 3217.2 & 2495.1 & 1.78 \\
$120 \times 120 \times 8.0-450-\mathrm{FR}$ & 117.1 & 5.28 & 8.09 & 6.27 & 2709.9 & 3417.9 & 2426.8 & 2.69 \\
$130 \times 130 \times 3.5-500-\mathrm{F}$ & 129.0 & 4.92 & 7.35 & 3.62 & 1848.8 & 2149.3 & 1652.0 & 1.53 \\
$130 \times 130 \times 3.5-500-\mathrm{FR}$ & 128.8 & 4.96 & 7.73 & 3.64 & 1824.2 & 2340.3 & 1636.4 & 1.41 \\
$150 \times 150 \times 3.5-600-\mathrm{F}$ & 149.8 & 4.37 & 6.67 & 4.05 & 2324.1 & 2633.8 & 2009.5 & 1.14 \\
$150 \times 150 \times 3.5-600-\mathrm{FR}$ & 149.7 & 4.22 & 7.11 & 4.00 & 2327.1 & 2737.4 & 1910.5 & 0.71 \\
$180 \times 180 \times 3.5-720-\mathrm{F}$ & 179.5 & 4.45 & 6.73 & 4.05 & 2832.3 & 3248.9 & 2419.5 & 1.13 \\
$180 \times 180 \times 3.5-720-\mathrm{FR}$ & 179.0 & 4.65 & 6.87 & 4.06 & 2874.1 & 4849.2 & 2380.8 & 3.80 \\
\hline
\end{tabular}

674

675 
676 Table 5: Comparison of geometric properties determined using different measurement methods

\begin{tabular}{|c|c|c|c|c|c|c|}
\hline Specimen ID & $A_{\mathrm{h}} / A_{\text {Arch }}$ & $A / A_{\text {Arch }}$ & $A / A_{\min }$ & $A / A_{\max }$ & $A_{\text {sd }} / A$ & $e_{\max } / t$ \\
\hline $60 \times 60 \times 3.5-240-F$ & 0.96 & 1.03 & 1.15 & 0.82 & 0.07 & 0.34 \\
\hline $60 \times 60 \times 3.5-240-\mathrm{FR}$ & 1.00 & 1.01 & 1.12 & 0.87 & 0.06 & 0.36 \\
\hline $80 \times 80 \times 3.5-320-\mathrm{F}$ & 0.97 & 1.03 & 1.15 & 0.79 & 0.07 & 0.41 \\
\hline $80 \times 80 \times 3.5-320-F R$ & 0.99 & 1.02 & 1.12 & 0.89 & 0.05 & 0.52 \\
\hline $100 \times 100 \times 3.5-400-F$ & 1.07 & 0.99 & 1.09 & 0.88 & 0.04 & 0.16 \\
\hline $100 \times 100 \times 3.5-400-F R$ & 1.11 & 1.01 & 1.12 & 0.89 & 0.05 & 0.18 \\
\hline $120 \times 120 \times 8.0-450-\mathrm{F}$ & 1.11 & 1.01 & 1.16 & 0.90 & 0.04 & 0.27 \\
\hline $120 \times 120 \times 8.0-450-\mathrm{FR}$ & 1.15 & 1.00 & 1.12 & 0.79 & 0.05 & 0.43 \\
\hline $130 \times 130 \times 3.5-500-\mathrm{F}$ & 1.08 & 1.00 & 1.12 & 0.86 & 0.05 & 0.42 \\
\hline $130 \times 130 \times 3.5-500-\mathrm{FR}$ & 1.19 & 1.00 & 1.11 & 0.78 & 0.08 & 0.39 \\
\hline $150 \times 150 \times 3.5-600-\mathrm{F}$ & 0.98 & 1.02 & 1.16 & 0.88 & 0.05 & 0.28 \\
\hline $150 \times 150 \times 3.5-600-\mathrm{FR}$ & 1.01 & 1.02 & 1.22 & 0.85 & 0.04 & 0.18 \\
\hline $180 \times 180 \times 3.5-720-\mathrm{F}$ & 1.00 & 1.02 & 1.17 & 0.87 & 0.04 & 0.28 \\
\hline $180 \times 180 \times 3.5-720-$ FR & 0.90 & 1.03 & 1.21 & 0.59 & 0.10 & 0.94 \\
\hline Mean & 1.04 & 1.01 & 1.14 & 0.83 & 0.06 & 0.37 \\
\hline $\mathrm{COV}$ & 0.08 & 0.01 & 0.03 & 0.09 & 0.29 & 0.51 \\
\hline
\end{tabular}

677

678

679

680

681 Table 6: Cumulative distribution function (CDF) values for imperfection amplitudes

682

\begin{tabular}{cc}
\hline $\mathrm{P}\left(e_{\max , \mathrm{r}}<e_{\max , \mathrm{d}}\right)$ & $e_{\max }(\mathrm{mm})$ \\
\hline 0.25 & 0.73 \\
0.50 & 1.28 \\
0.75 & 1.50 \\
0.90 & 2.05 \\
0.95 & 2.94 \\
0.99 & 3.80 \\
Mean & 1.29 \\
St. Dev. & 0.68 \\
\hline
\end{tabular}

683

684

685 


\begin{tabular}{lcc}
\hline Specimen ID & $N_{\mathrm{u}}(\mathrm{kN})$ & $\delta_{\mathrm{u}}(\mathrm{mm})$ \\
\hline $60 \times 60 \times 3.5-240-\mathrm{F}$ & 277.5 & 5.84 \\
$60 \times 60 \times 3.5-240-\mathrm{FR}$ & 250.6 & 5.74 \\
$80 \times 80 \times 3.5-320-\mathrm{F}$ & 353.0 & 3.69 \\
$80 \times 80 \times 3.5-320-\mathrm{FR}$ & 314.1 & 3.25 \\
$100 \times 100 \times 3.5-400-\mathrm{F}$ & 440.8 & 2.86 \\
$100 \times 100 \times 3.5-400-\mathrm{FR}$ & 437.6 & 2.81 \\
$120 \times 120 \times 8.0-450-\mathrm{F}$ & 993.2 & 8.86 \\
$120 \times 120 \times 8.0-450-\mathrm{FR}$ & 841.1 & 6.64 \\
$130 \times 130 \times 3.5-500-\mathrm{F}$ & 437.4 & 2.23 \\
$130 \times 130 \times 3.5-500-\mathrm{FR}$ & 414.8 & 1.87 \\
$150 \times 150 \times 3.5-600-\mathrm{F}$ & 520.3 & 2.27 \\
$150 \times 150 \times 3.5-600-\mathrm{FR}$ & 556.1 & 2.34 \\
$180 \times 180 \times 3.5-720-\mathrm{F}$ & 528.1 & 1.89 \\
$180 \times 180 \times 3.5-720-\mathrm{FR}$ & 468.1 & 2.26 \\
\hline
\end{tabular}

687

688

689

690

Table 8: Comparisons of test results with AISC 370 design predictions

\begin{tabular}{|c|c|c|c|c|c|c|c|c|}
\hline \multirow{2}{*}{$\begin{array}{c}\text { Test } \\
\begin{array}{c}N_{\mathrm{u}} \\
(\mathrm{kN})\end{array}\end{array}$} & \multicolumn{3}{|c|}{$\begin{array}{l}\text { AISC } 370 \text { predictions } \\
\text { (machined properties) }\end{array}$} & \multicolumn{3}{|c|}{$\begin{array}{c}\text { AISC } 370 \text { predictions } \\
\text { (effective properties) }\end{array}$} & \multicolumn{2}{|c|}{ Comparisons } \\
\hline & Class & $\lambda \sqrt{\sigma_{0.2} / E}$ & $\begin{array}{l}N_{\mathrm{u}, \mathrm{AISC}, \mathrm{m}} \\
(\mathrm{kN})\end{array}$ & Class & $\lambda \sqrt{\sigma_{0.2} / E}$ & $\begin{array}{l}N_{\mathrm{u}, \text { AISC, eff }} \\
(\mathrm{kN})\end{array}$ & $\begin{array}{c}N_{\mathrm{u}} / \\
N_{\mathrm{u}, \mathrm{AISC}, \mathrm{m}}\end{array}$ & $\begin{array}{c}N_{\mathrm{u}} / \\
N_{\mathrm{u}, \mathrm{AISC}, \mathrm{eff}}\end{array}$ \\
\hline 277.5 & Non slender & 0.53 & 309.2 & Non slender & 0.58 & 238.8 & 0.90 & 1.16 \\
\hline 250.6 & Non slender & 0.56 & 285.1 & Non slender & 0.62 & 220.2 & 0.88 & 1.14 \\
\hline 353.0 & Non slender & 0.78 & 414.9 & Non slender & 0.85 & 320.4 & 0.85 & 1.10 \\
\hline 314.1 & Non slender & 0.81 & 399.6 & Non slender & 0.89 & 308.6 & 0.79 & 1.02 \\
\hline 440.8 & Non slender & 1.05 & 505.9 & Non slender & 1.15 & 390.6 & 0.87 & 1.13 \\
\hline 437.6 & Non slender & 1.05 & 513.8 & Non slender & 1.14 & 396.8 & 0.85 & 1.10 \\
\hline 993.2 & Non slender & 0.74 & 978.2 & Non slender & 0.75 & 784.3 & 1.02 & 1.27 \\
\hline 841.1 & Non slender & 0.76 & 915.9 & Non slender & 0.77 & 734.4 & 0.92 & 1.15 \\
\hline 437.4 & Slender & 1.54 & 534.7 & Slender & 1.68 & 386.3 & 0.82 & 1.13 \\
\hline 414.8 & Slender & 1.52 & 530.8 & Slender & 1.66 & 383.2 & 0.78 & 1.08 \\
\hline 520.3 & Slender & 1.64 & 632.7 & Slender & 1.79 & 454.7 & 0.82 & 1.14 \\
\hline 556.1 & Slender & 1.65 & 631.3 & Slender & 1.81 & 454.3 & 0.88 & 1.22 \\
\hline 528.1 & Slender & 2.00 & 656.5 & Slender & 2.18 & 471.4 & 0.80 & 1.12 \\
\hline \multirow[t]{3}{*}{468.1} & Slender & 1.98 & 675.7 & Slender & 2.16 & 486.0 & 0.69 & 0.96 \\
\hline & & & & & & Mean & 0.85 & 1.12 \\
\hline & & & & & & $\mathrm{COV}$ & 0.09 & 0.06 \\
\hline
\end{tabular}

691

692 
Table 9: Comparisons of test results with EN 1993-1-4 design predictions

\begin{tabular}{|c|c|c|c|c|c|c|c|c|c|}
\hline \multirow[b]{3}{*}{ Specimen ID } & \multirow{3}{*}{$\begin{array}{c}\text { Test } \\
\begin{array}{c}N_{\mathrm{u}} \\
(\mathrm{kN})\end{array}\end{array}$} & & & & & & & & \\
\hline & & \multicolumn{3}{|c|}{$\begin{array}{l}\text { EN1993-1-4 predictions } \\
\text { (machined properties) }\end{array}$} & \multicolumn{3}{|c|}{$\begin{array}{l}\text { EN1993-1-4 predictions } \\
\text { (effective properties) }\end{array}$} & \multicolumn{2}{|c|}{ Comparisons } \\
\hline & & Class & $c /(t \varepsilon)$ & $\begin{array}{c}N_{\mathrm{u}, \mathrm{EN}, \mathrm{m}} \\
(\mathrm{kN})\end{array}$ & Class & $c /(t \varepsilon)$ & $\begin{array}{l}N_{\mathrm{u}, \mathrm{EN}, \mathrm{eff}} \\
(\mathrm{kN})\end{array}$ & $\begin{array}{c}N_{\mathrm{u}} / \\
N_{\mathrm{u}, \mathrm{EN}, \mathrm{m}}\end{array}$ & $\begin{array}{c}N_{\mathrm{u}} / \\
N_{\mathrm{u}, \mathrm{EN}, \mathrm{eff}}\end{array}$ \\
\hline $60 \times 60 \times 3.5-240-F$ & 277.5 & 1 & 15.8 & 309.2 & 1 & 17.3 & 238.8 & 0.90 & 1.16 \\
\hline $60 \times 60 \times 3.5-240-\mathrm{FR}$ & 250.6 & 1 & 16.9 & 285.1 & 1 & 18.5 & 220.2 & 0.88 & 1.14 \\
\hline $80 \times 80 \times 3.5-320-F$ & 353.0 & 1 & 23.3 & 414.9 & 1 & 25.5 & 320.4 & 0.85 & 1.10 \\
\hline $80 \times 80 \times 3.5-320-F R$ & 314.1 & 1 & 24.3 & 399.6 & 1 & 26.5 & 308.6 & 0.79 & 1.02 \\
\hline $100 \times 100 \times 3.5-400-\mathrm{F}$ & 440.8 & 1 & 31.4 & 505.9 & 2 & 34.3 & 390.6 & 0.87 & 1.13 \\
\hline $100 \times 100 \times 3.5-400-F R$ & 437.6 & 1 & 31.3 & 513.8 & 2 & 34.2 & 396.8 & 0.85 & 1.10 \\
\hline $120 \times 120 \times 8.0-450-\mathrm{F}$ & 993.2 & 1 & 22.0 & 978.2 & 1 & 22.3 & 784.3 & 1.02 & 1.27 \\
\hline $120 \times 120 \times 8.0-450-\mathrm{FR}$ & 841.1 & 1 & 22.9 & 915.9 & 1 & 23.2 & 734.4 & 0.92 & 1.15 \\
\hline $130 \times 130 \times 3.5-500-\mathrm{F}$ & 437.4 & 4 & 45.9 & 532.0 & 4 & 50.2 & 384.6 & 0.82 & 1.14 \\
\hline $130 \times 130 \times 3.5-500-\mathrm{FR}$ & 414.8 & 4 & 45.4 & 528.2 & 4 & 49.7 & 381.4 & 0.79 & 1.09 \\
\hline $150 \times 150 \times 3.5-600-\mathrm{F}$ & 520.3 & 4 & 48.9 & 629.6 & 4 & 53.5 & 452.7 & 0.83 & 1.15 \\
\hline $150 \times 150 \times 3.5-600-\mathrm{FR}$ & 556.1 & 4 & 49.4 & 628.3 & 4 & 54.0 & 452.4 & 0.89 & 1.23 \\
\hline $180 \times 180 \times 3.5-720-\mathrm{F}$ & 528.1 & 4 & 59.6 & 653.9 & 4 & 65.2 & 469.6 & 0.81 & 1.12 \\
\hline \multirow[t]{3}{*}{$180 \times 180 \times 3.5-720-$ FR } & 468.1 & 4 & 59.2 & 673.0 & 4 & 64.7 & 484.3 & 0.70 & 0.97 \\
\hline & & & & & & & Mean & 0.85 & 1.13 \\
\hline & & & & & & & $\mathrm{COV}$ & 0.08 & 0.06 \\
\hline
\end{tabular}

694

695

Table 10: Comparisons of test results with CSM design predictions

\begin{tabular}{cccc}
\hline Test & $\begin{array}{c}\text { CSM predictions } \\
\text { (machined properties) }\end{array}$ & $\begin{array}{c}\text { CSM predictions } \\
\text { (effective properties) }\end{array}$ & Comparisons \\
\hline
\end{tabular}

\begin{tabular}{lccccccccc}
\cline { 2 - 9 } Specimen ID & $\begin{array}{c}N_{\mathrm{u}} \\
(\mathrm{kN})\end{array}$ & $\bar{\lambda}_{p, c s}$ & $\varepsilon_{\mathrm{csm}} / \varepsilon_{\mathrm{y}}$ & $\begin{array}{c}N_{\mathrm{u}, \mathrm{csm}, \mathrm{m}} \\
(\mathrm{kN})\end{array}$ & $\bar{\lambda}_{p, c s}$ & $\varepsilon_{\mathrm{csm}} / \varepsilon_{\mathrm{y}}$ & $\begin{array}{c}N_{\mathrm{u}, \text { csm,eff }} \\
(\mathrm{kN})\end{array}$ & $\begin{array}{c}N_{\mathrm{u}} / \\
N_{\mathrm{u}, \mathrm{csm}, \mathrm{m}}\end{array}$ & $\begin{array}{c}N_{\mathrm{u}} / \\
N_{\mathrm{u}, \mathrm{csm}, \mathrm{eff}}\end{array}$ \\
\hline $60 \times 60 \times 3.5-240-\mathrm{F}$ & 277.5 & 0.28 & 15.00 & 420.9 & 0.30 & 14.43 & 342.8 & 0.66 & 0.81 \\
$60 \times 60 \times 3.5-240-\mathrm{FR}$ & 250.6 & 0.30 & 15.00 & 388.1 & 0.32 & 14.36 & 315.6 & 0.65 & 0.79 \\
$80 \times 80 \times 3.5-320-\mathrm{F}$ & 353.0 & 0.41 & 6.16 & 470.1 & 0.45 & 4.47 & 356.4 & 0.75 & 0.99 \\
$80 \times 80 \times 3.5-320-\mathrm{FR}$ & 314.1 & 0.43 & 5.36 & 444.5 & 0.47 & 3.89 & 337.4 & 0.71 & 0.93 \\
$100 \times 100 \times 3.5-400-\mathrm{F}$ & 440.8 & 0.55 & 2.12 & 520.5 & 0.60 & 1.54 & 397.5 & 0.85 & 1.11 \\
$100 \times 100 \times 3.5-400-\mathrm{FR}$ & 437.6 & 0.55 & 2.15 & 529.0 & 0.60 & 1.56 & 404.0 & 0.83 & 1.08 \\
$120 \times 120 \times 8.0-450-\mathrm{F}$ & 993.2 & 0.39 & 7.61 & 1145.0 & 0.39 & 7.27 & 908.8 & 0.87 & 1.09 \\
$120 \times 120 \times 8.0-450-\mathrm{FR}$ & 841.1 & 0.40 & 6.64 & 1049.2 & 0.41 & 6.34 & 833.7 & 0.80 & 1.01 \\
$130 \times 130 \times 3.5-500-\mathrm{F}$ & 437.4 & 0.81 & 0.90 & 564.5 & 0.88 & 0.85 & 410.6 & 0.77 & 1.07 \\
$130 \times 130 \times 3.5-500-\mathrm{FR}$ & 414.8 & 0.80 & 0.91 & 561.0 & 0.87 & 0.86 & 408.3 & 0.74 & 1.02 \\
$150 \times 150 \times 3.5-600-\mathrm{F}$ & 520.3 & 0.86 & 0.87 & 680.6 & 0.94 & 0.81 & 493.6 & 0.76 & 1.05 \\
$150 \times 150 \times 3.5-600-\mathrm{FR}$ & 556.1 & 0.87 & 0.86 & 677.2 & 0.95 & 0.81 & 490.9 & 0.82 & 1.13 \\
$180 \times 180 \times 3.5-720-\mathrm{F}$ & 528.1 & 1.05 & 0.75 & 718.0 & 1.15 & 0.70 & 517.0 & 0.74 & 1.02 \\
$180 \times 180 \times 3.5-720-\mathrm{FR}$ & 468.1 & 1.04 & 0.75 & 732.9 & 1.14 & 0.70 & 527.8 & 0.64 & 0.89 \\
\hline & & & & & & & Mean & 0.76 & 1.00 \\
& & & & & & & $\mathrm{COV}$ & 0.09 & 0.10
\end{tabular}


697
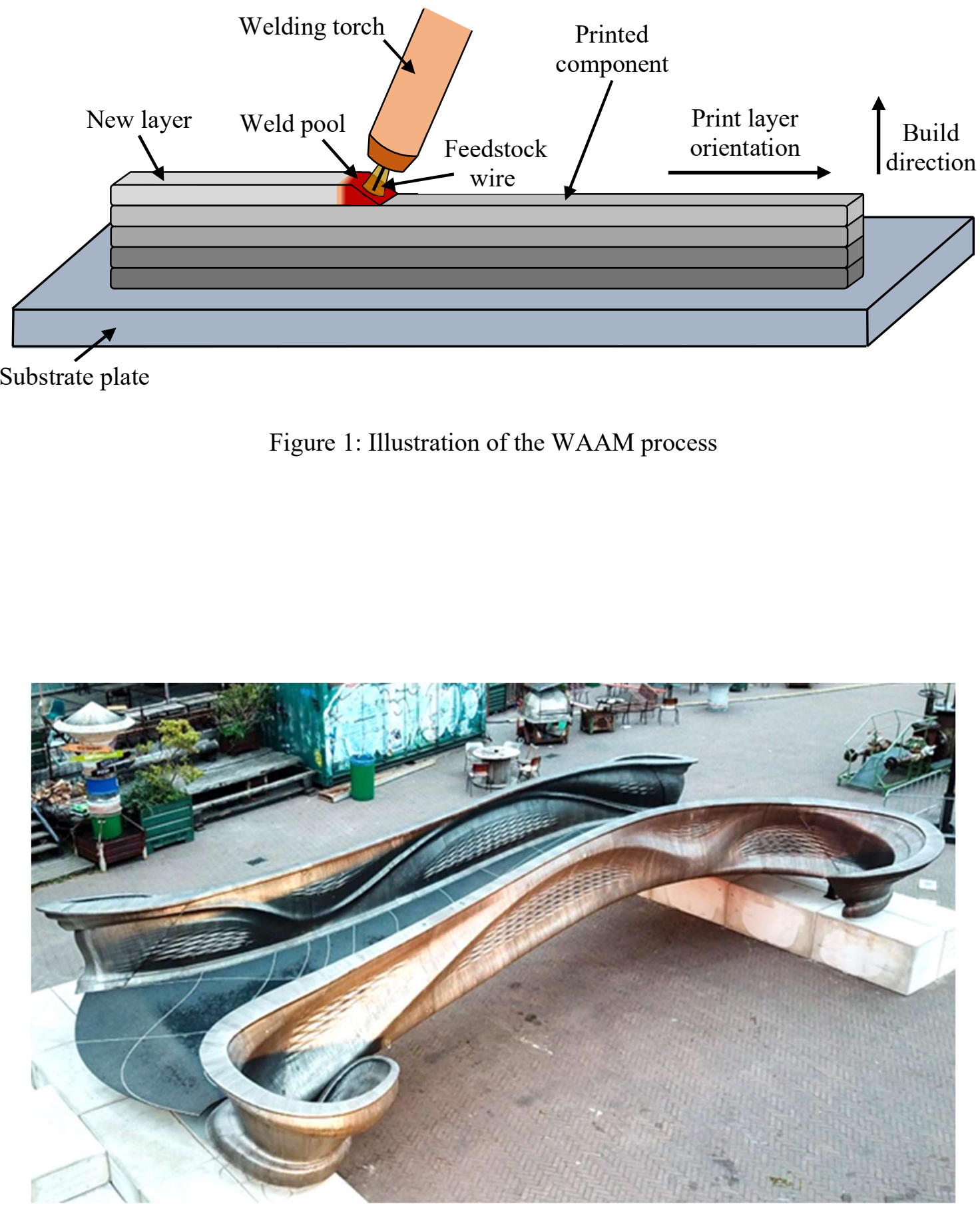

Figure 2: Overall view of MX3D Bridge (Gardner et al., 2020) 


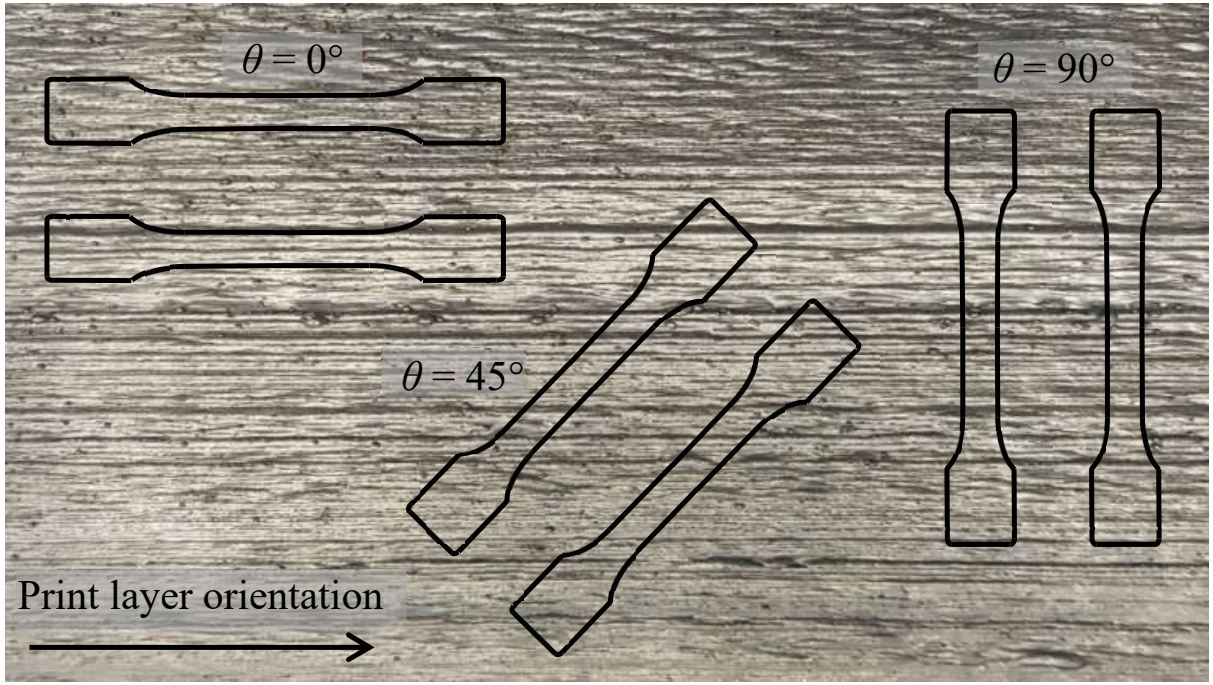

Figure 3: Orientation of tensile coupons extracted from WAAM plate relative to print layer orientation (Kyvelou et al., 2020)

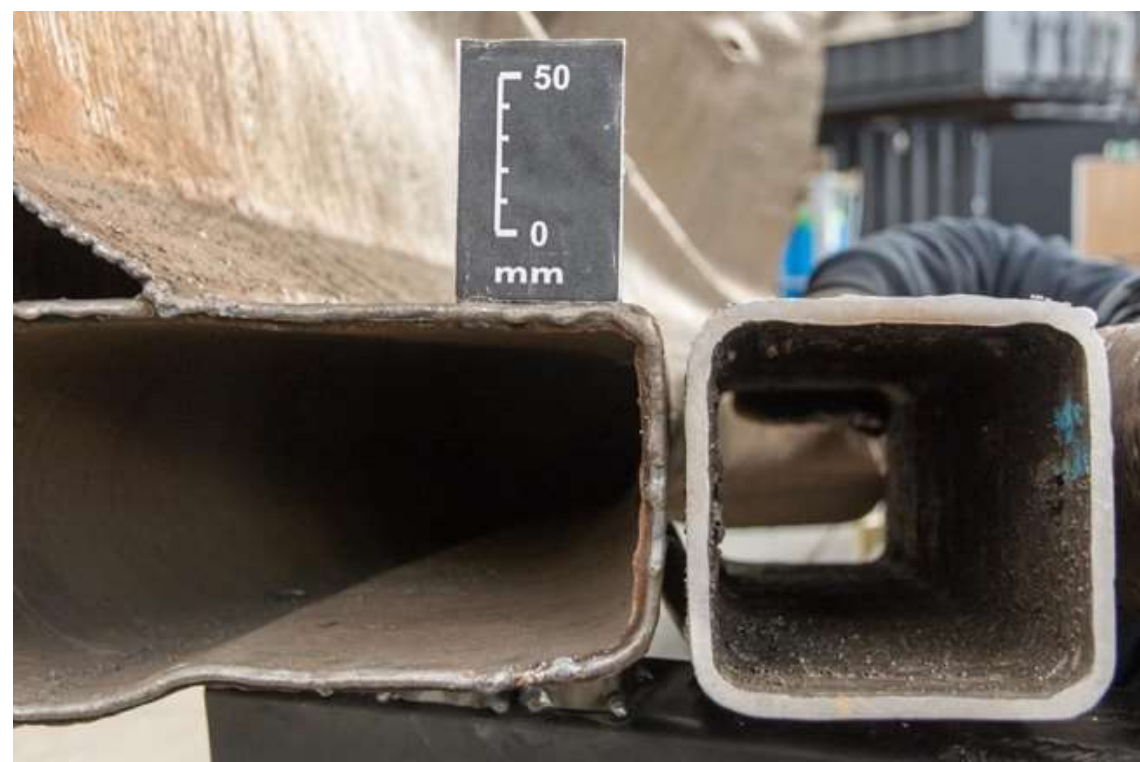

715 Figure 4: Comparison between SHS specimen $120 \times 120 \times 8.0-450-\mathrm{F}$ and its corresponding part of the MX3D Bridge (Gardner et al., 2020) 


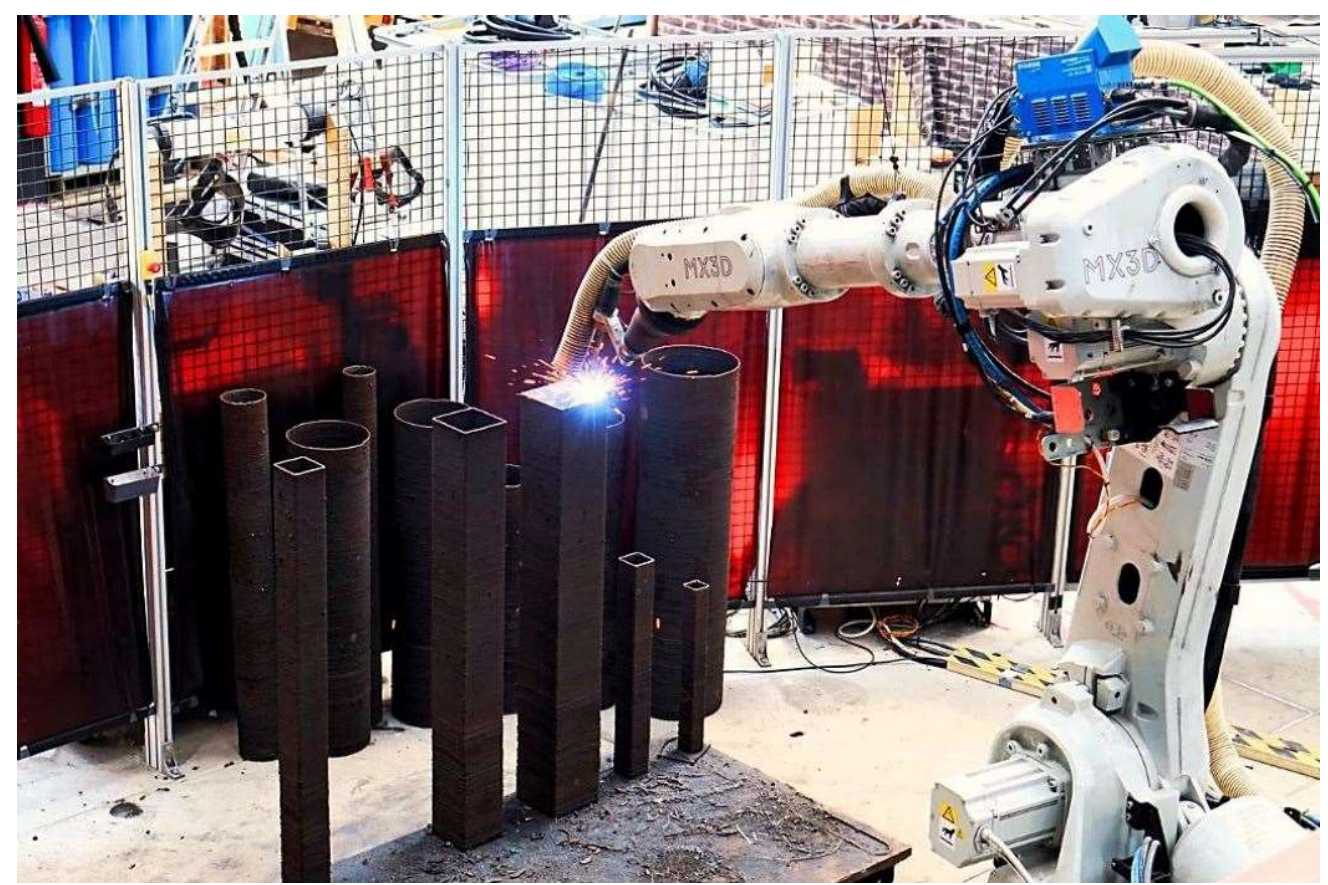

Figure 5: Printing of a subset of the SHS (and CHS) WAAM specimens

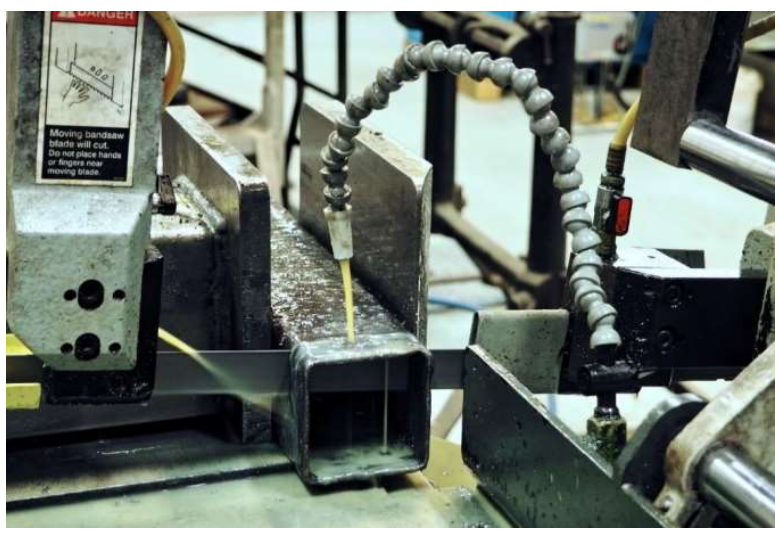

(a) Cutting using a band saw

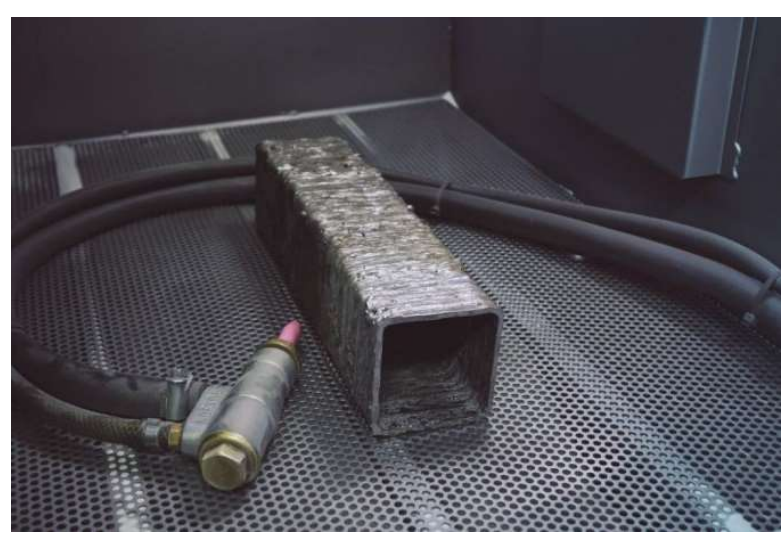

(b) Sand-blasting with glass beads 


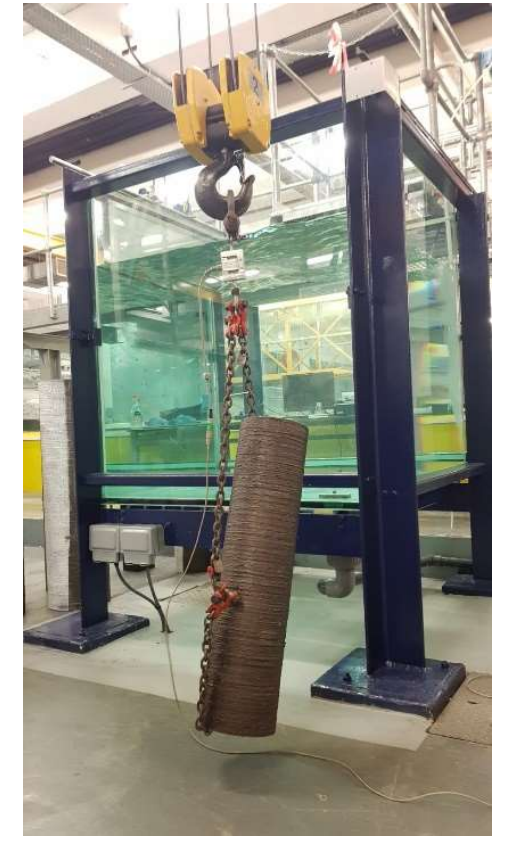

(a) Archimedes' measurements (shown for a CHS)

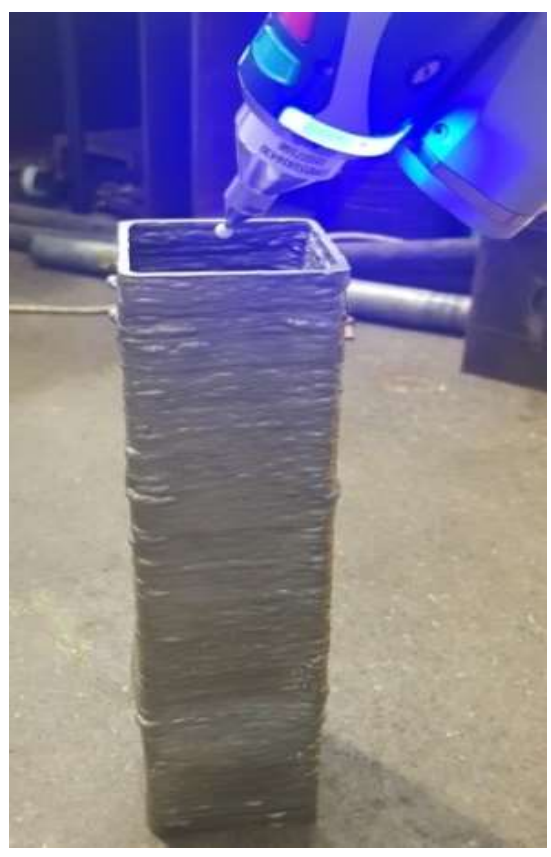

(b) Laser scanning
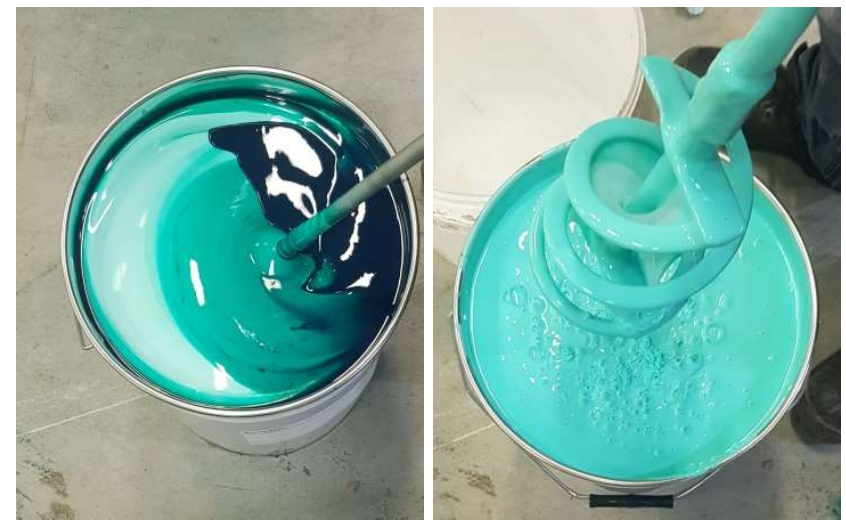

(a) Mixing silicone parts

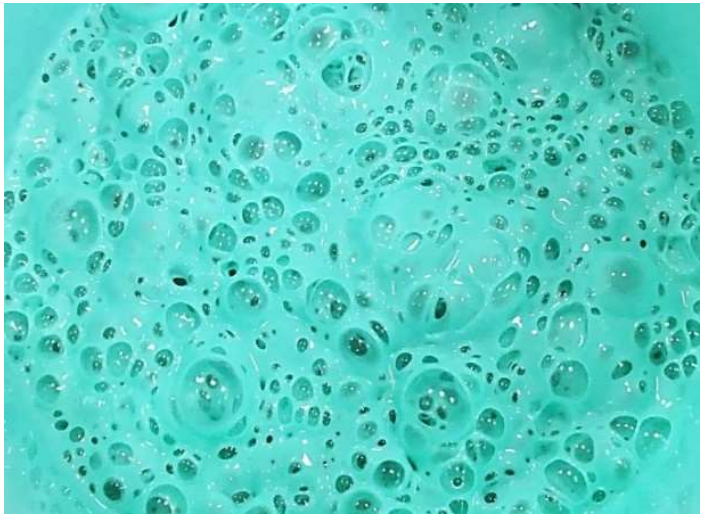

(b) Degassing

Figure 8: Preparation of silicone mixture 


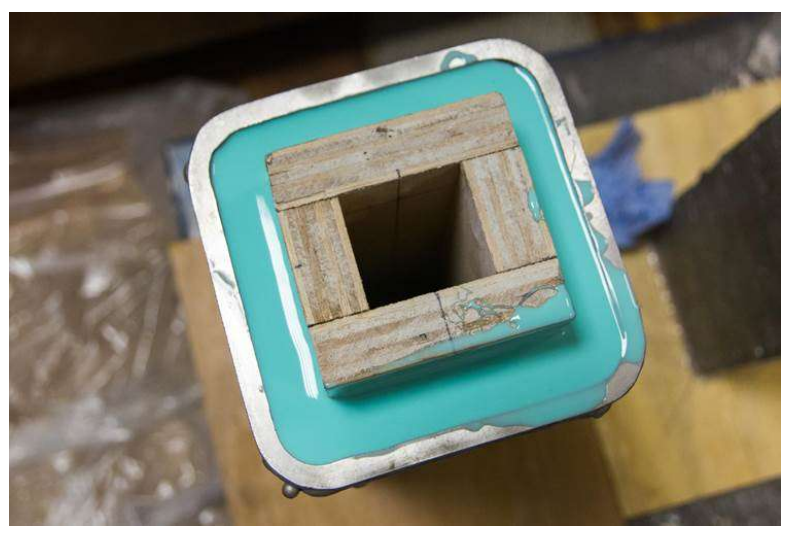

(a) Wooden insert within SHS

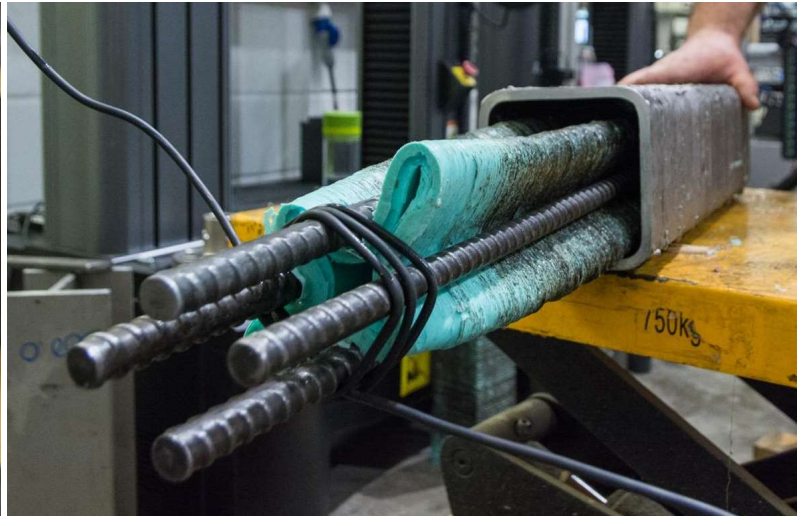

(b) Removal of silicone cast from within the SHS
735

737

738

739

740

741

742

743

744

745

746

747

748
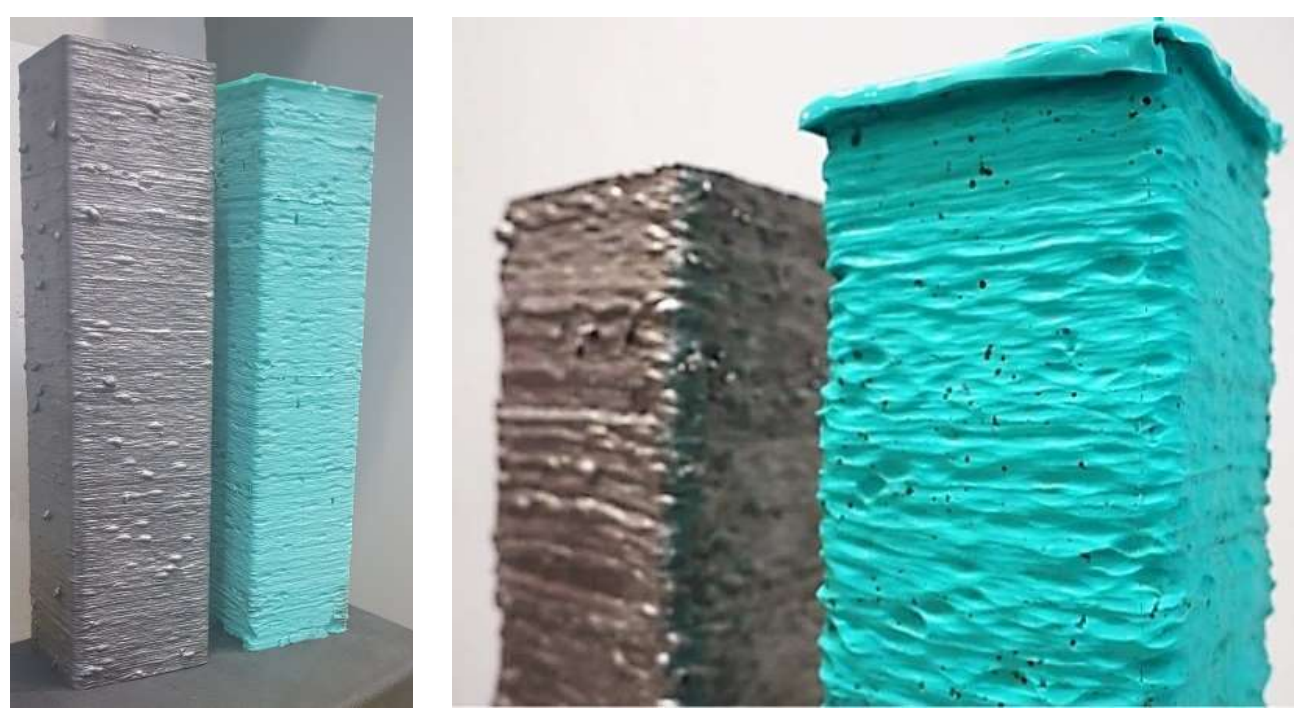

Figure 10: Silicone replica of the inner surface profile of typical SHS specimens 


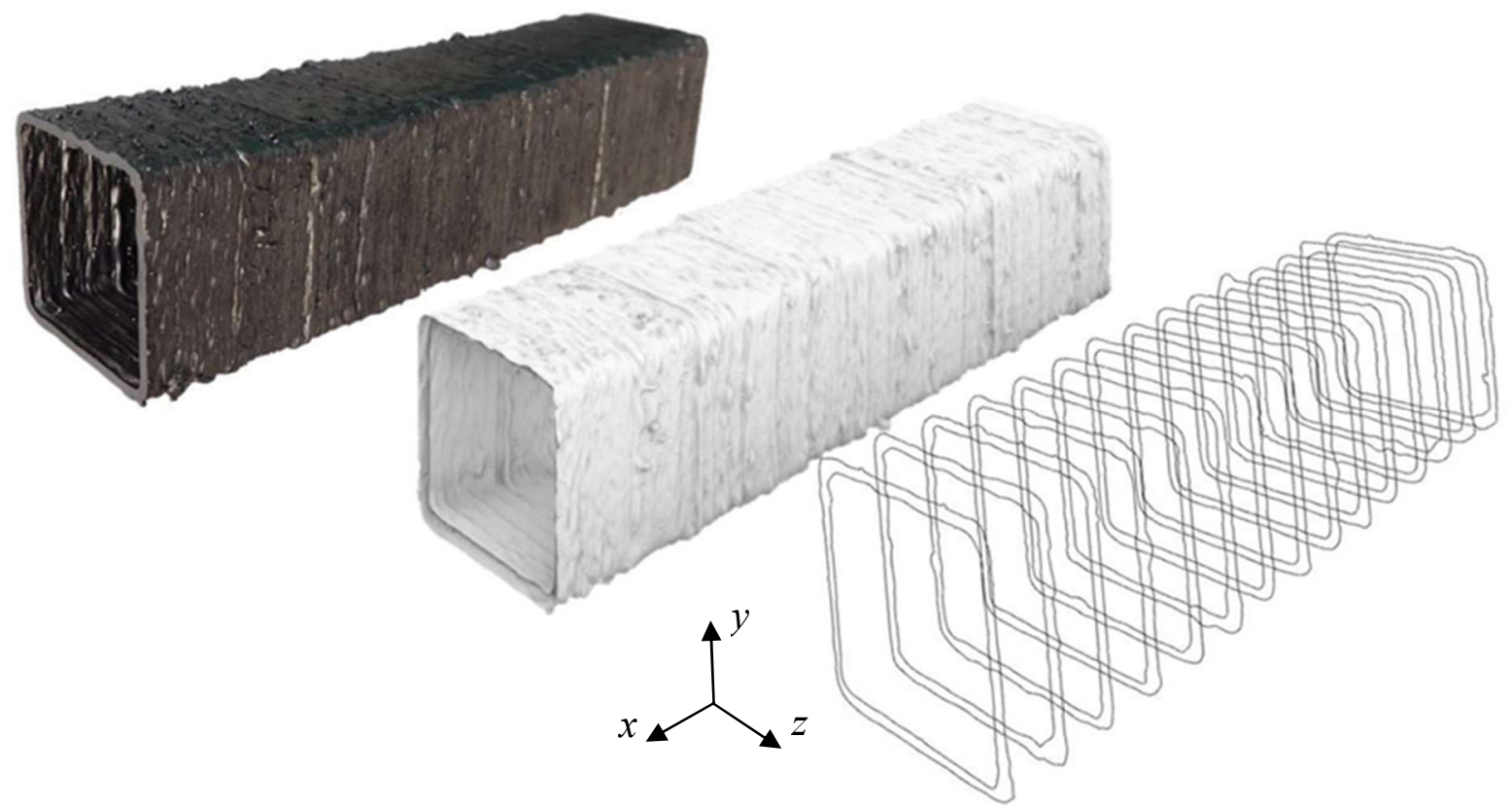

751

Figure 11: Specimen, 3D CAD model and cross-sectional contours of a typical SHS specimen

753

754

755

756

757

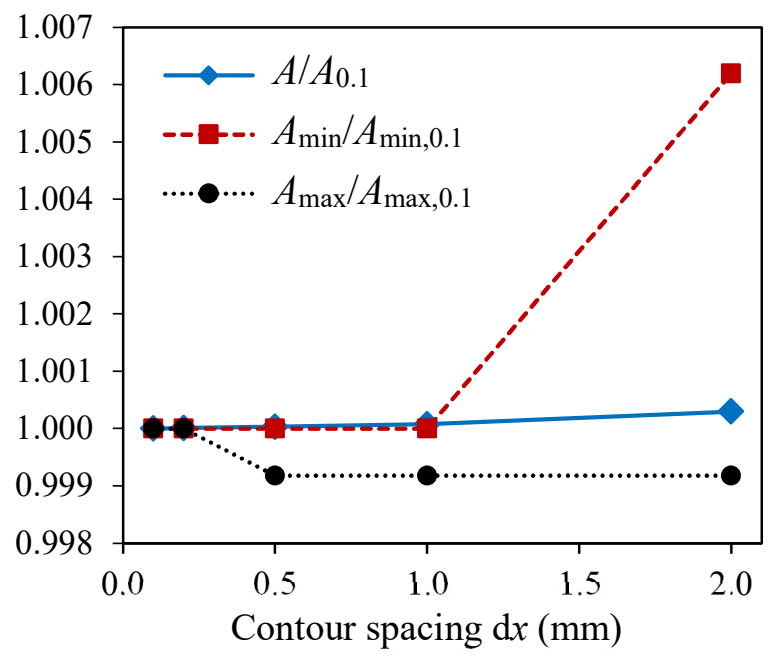

758

(a) $80 \times 80 \times 3.5-320-F$

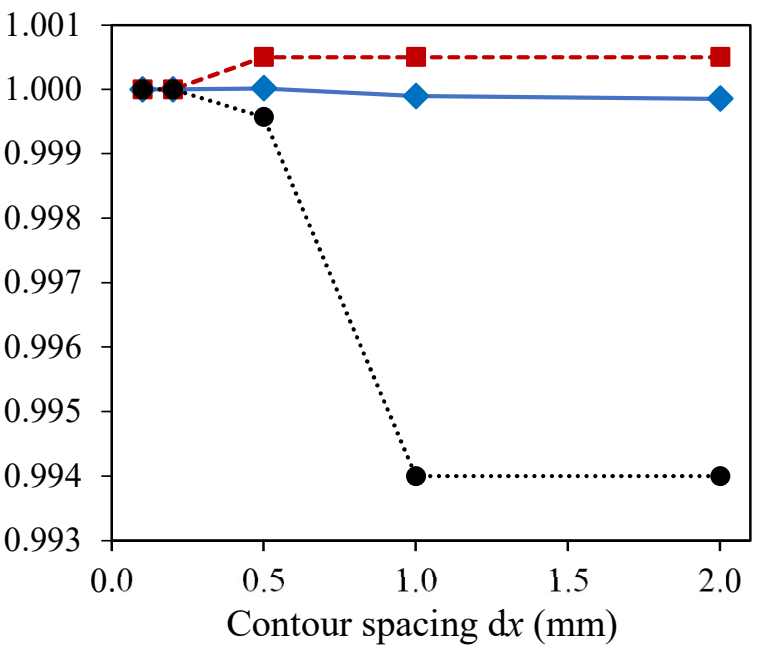

(b) $80 \times 80 \times 3.5-320-\mathrm{FR}$

Figure 12: Results of sensitivity study on contour spacing 

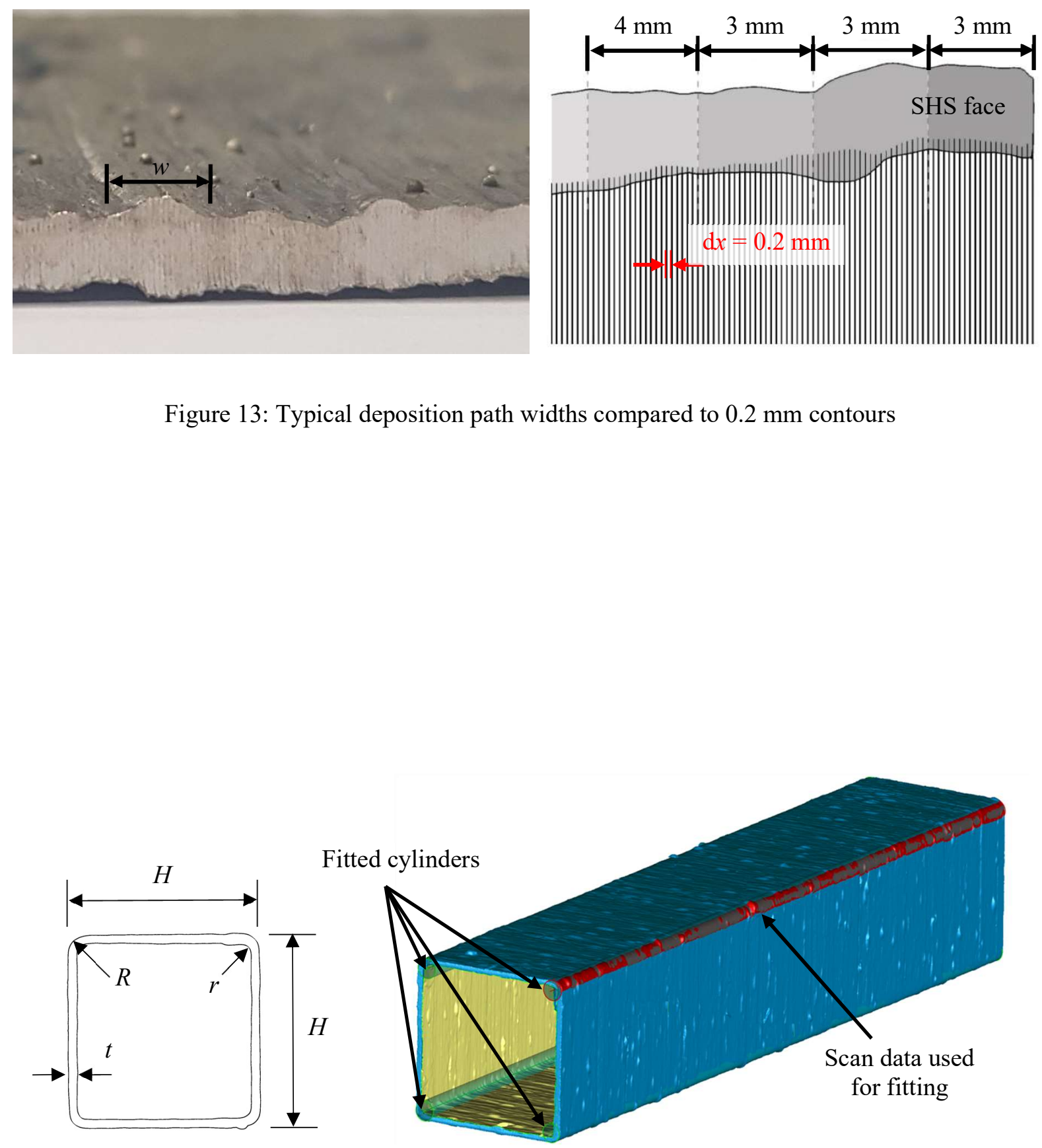

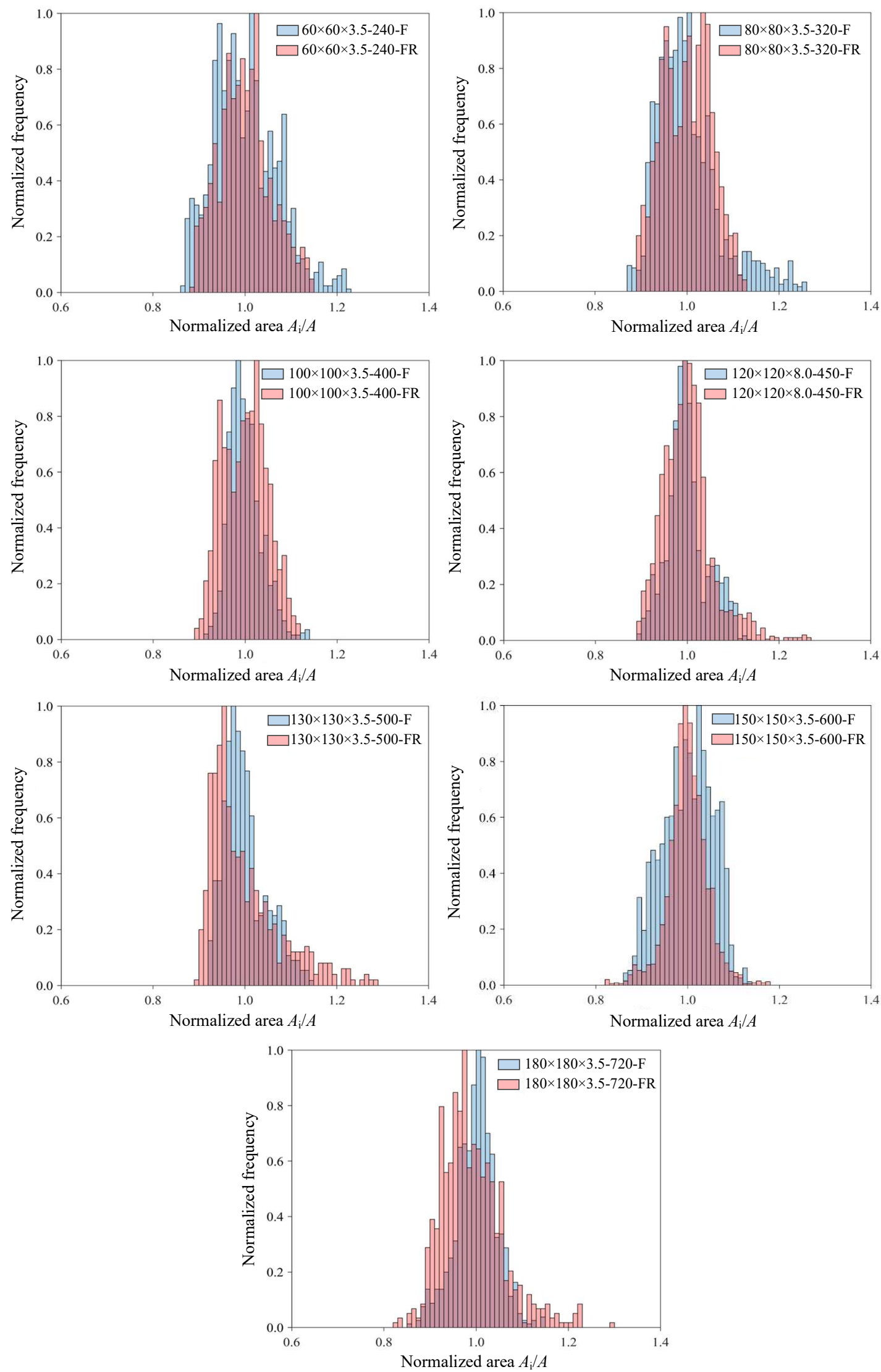

Figure 15: Distribution of normalized areas $A_{\mathrm{i}} / A$ of examined specimens 

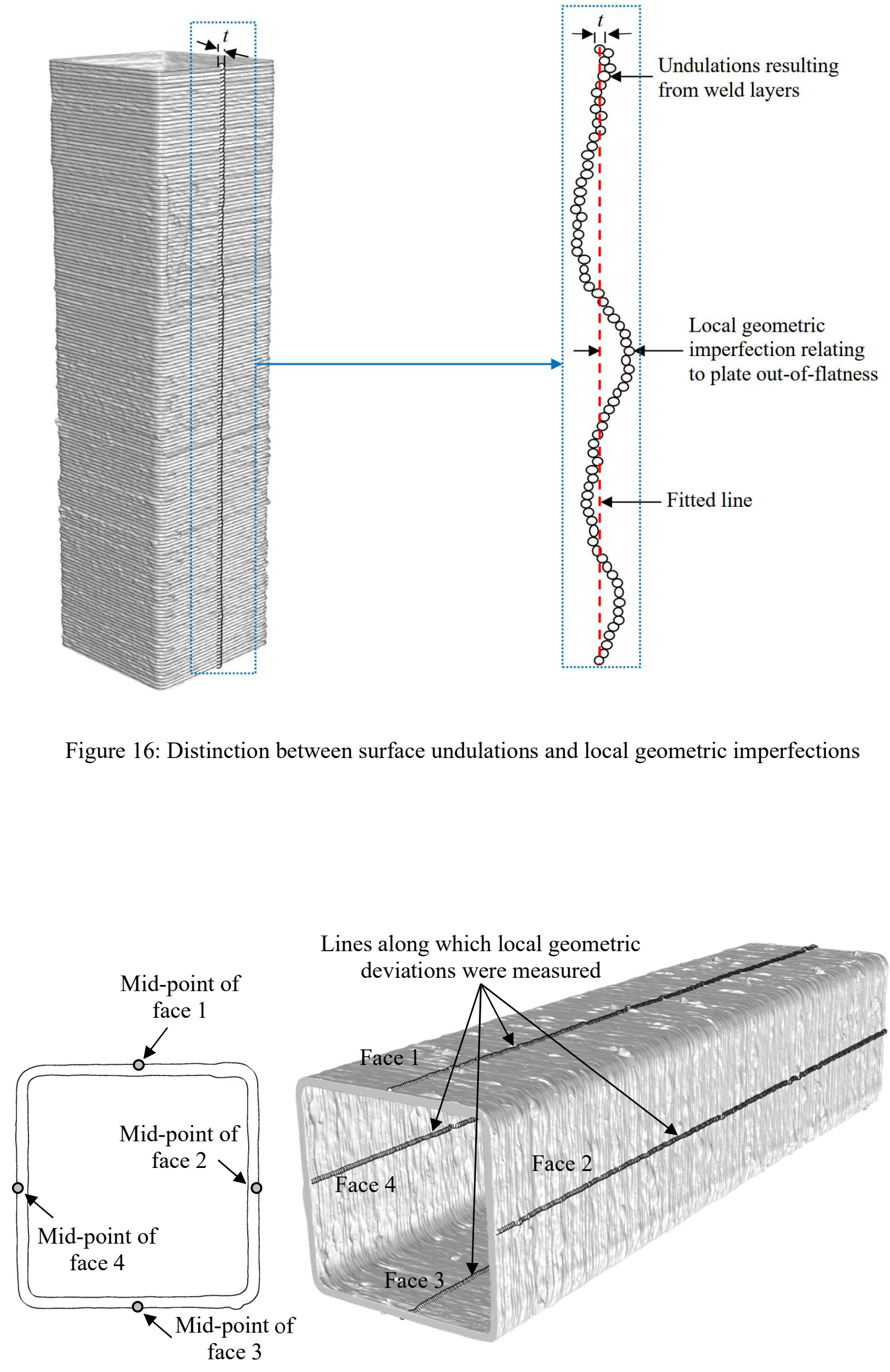

Figure 17: Determination of local geometric imperfections 


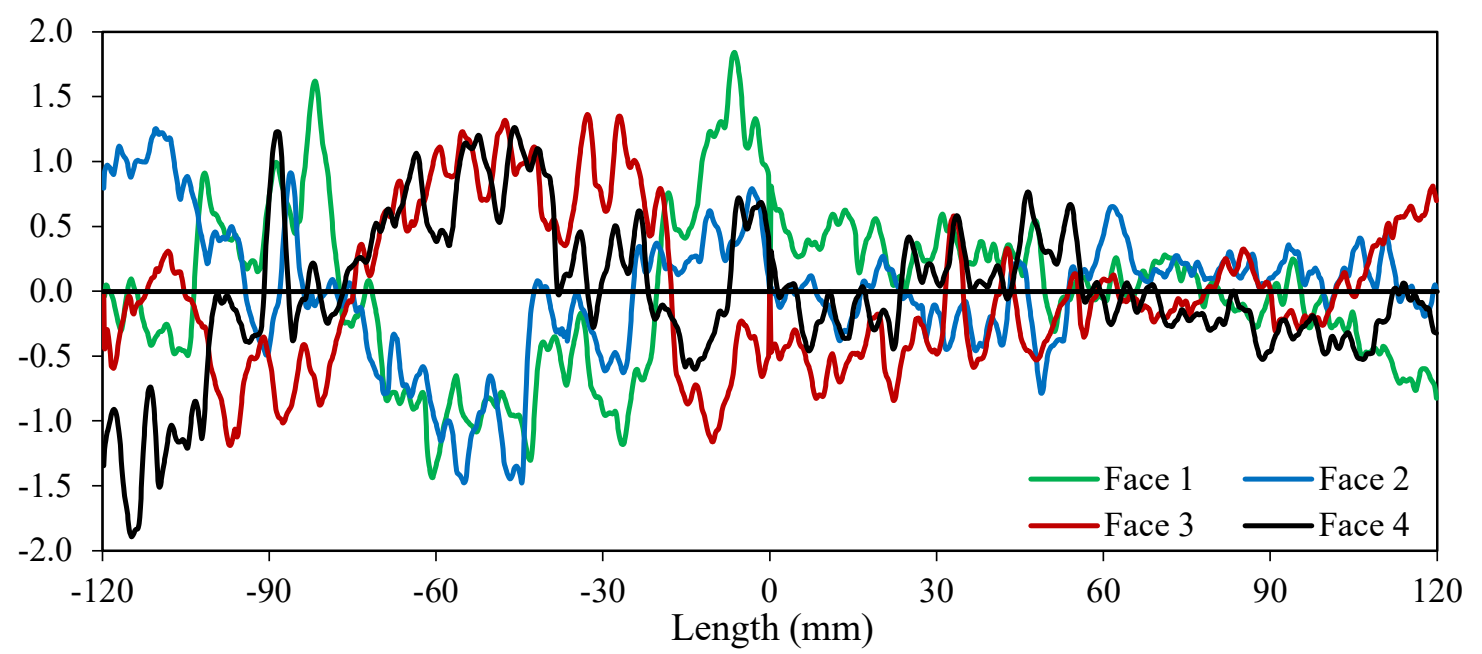

(a) Imperfection distributions before smoothing

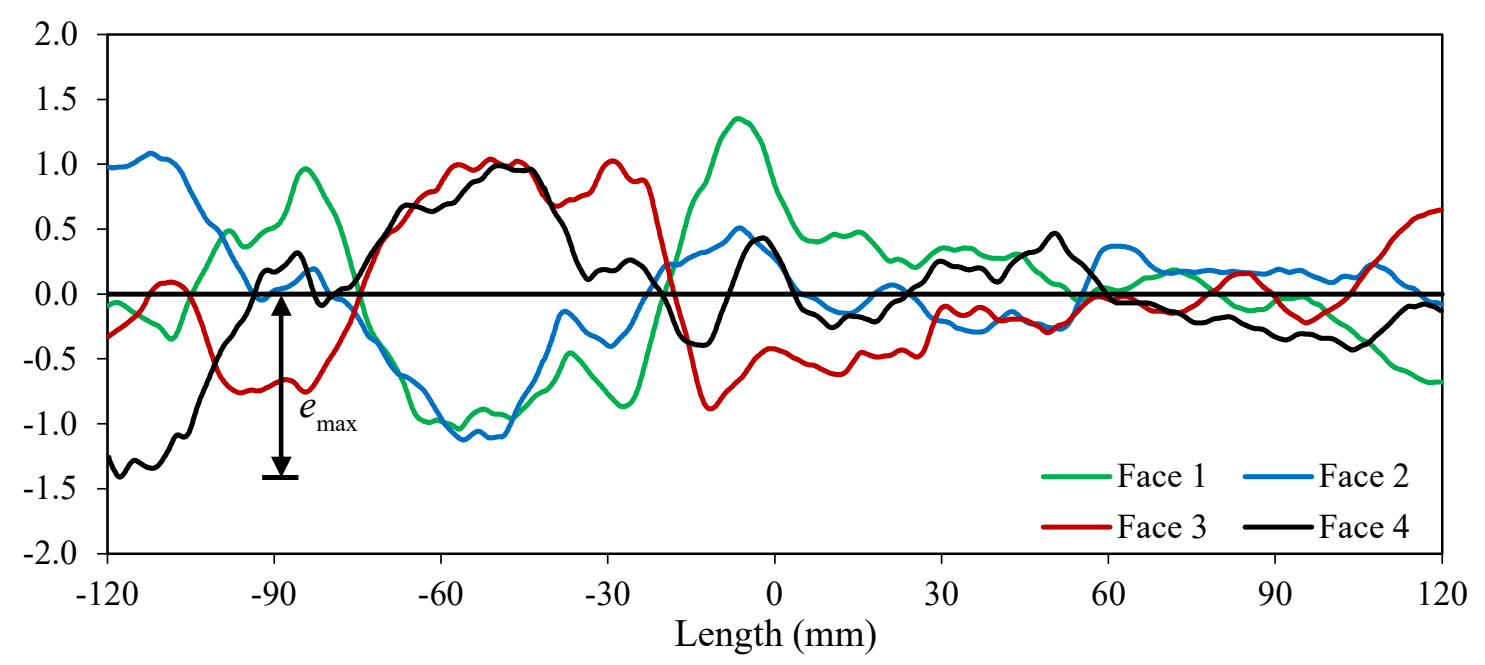

(b) Imperfection distributions after smoothing

Figure 18: Smoothing of local imperfection distributions to remove influence of unwanted features 


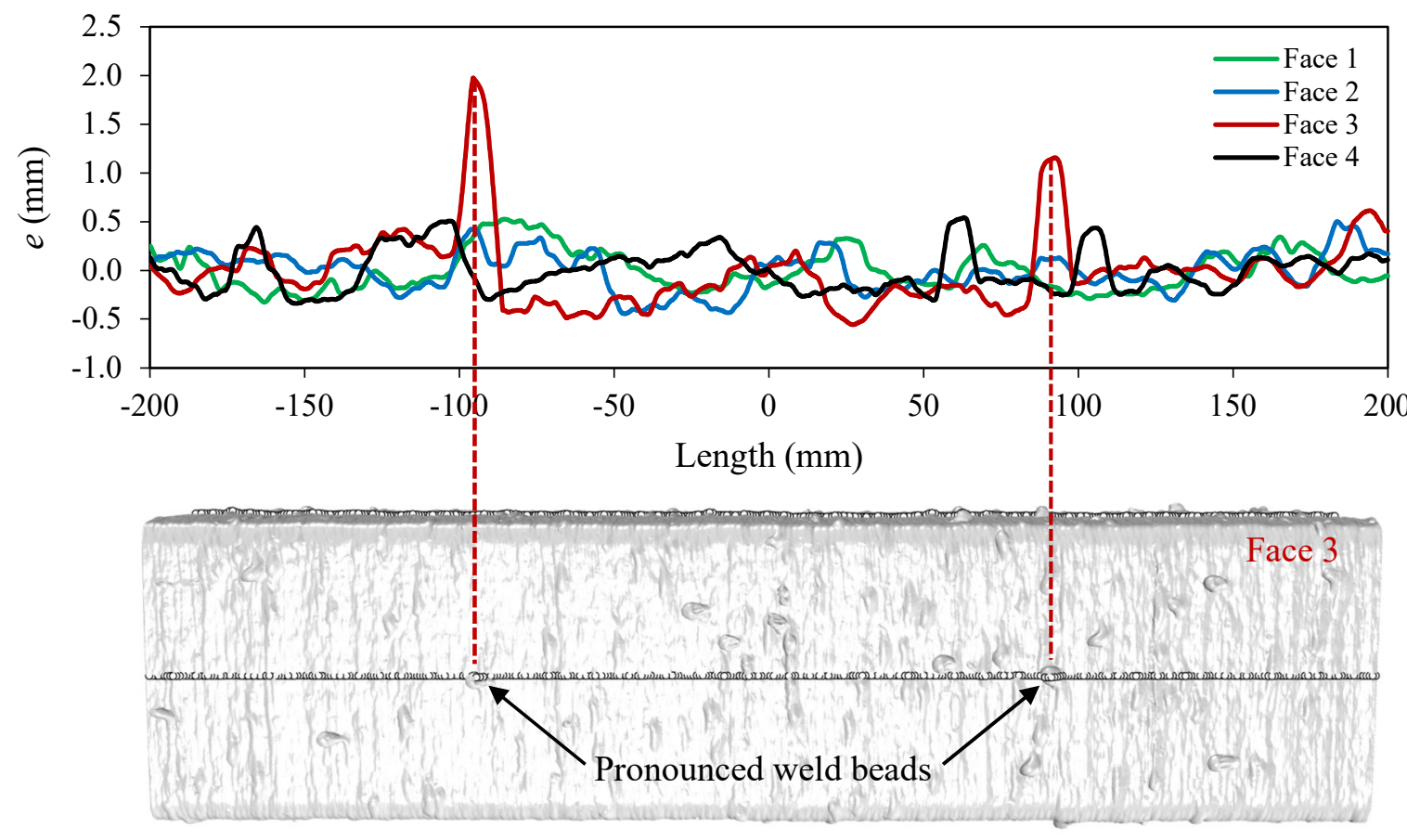

Figure 19: Measured local imperfection distributions for specimen $100 \times 100 \times 3.5-400-\mathrm{F}$

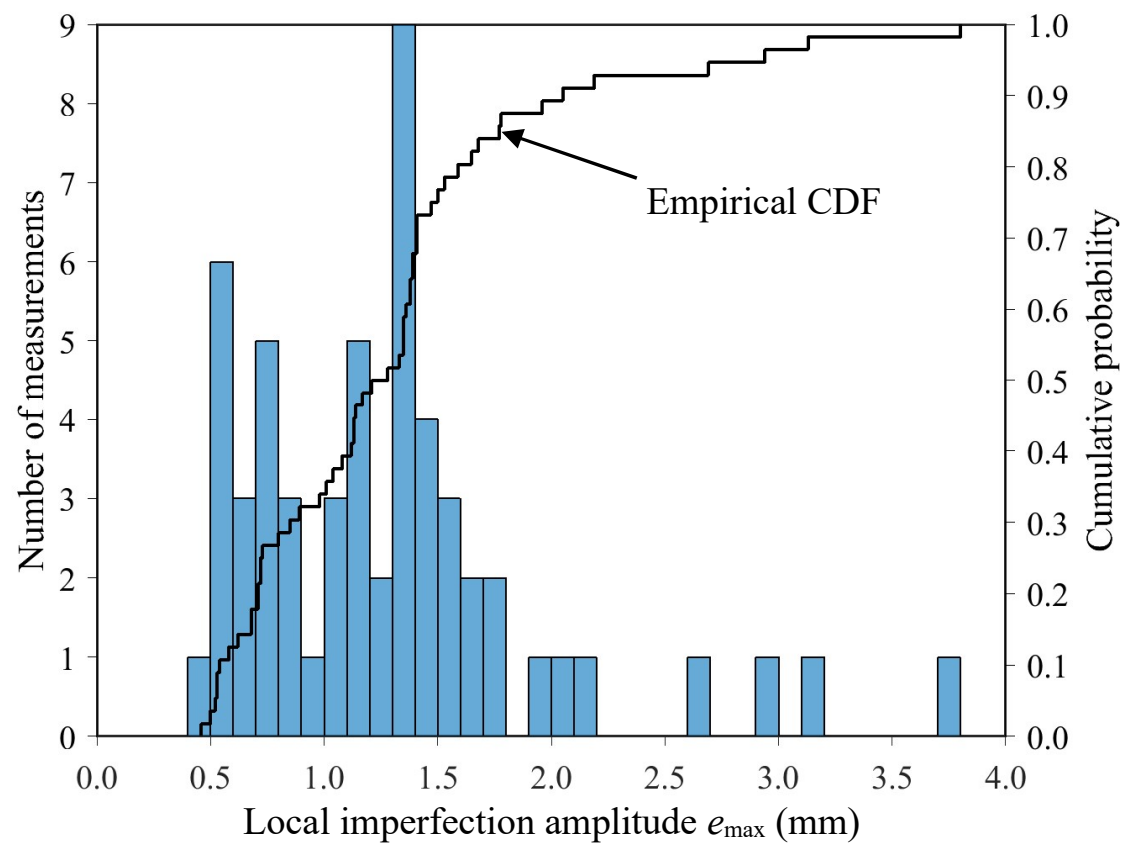


801
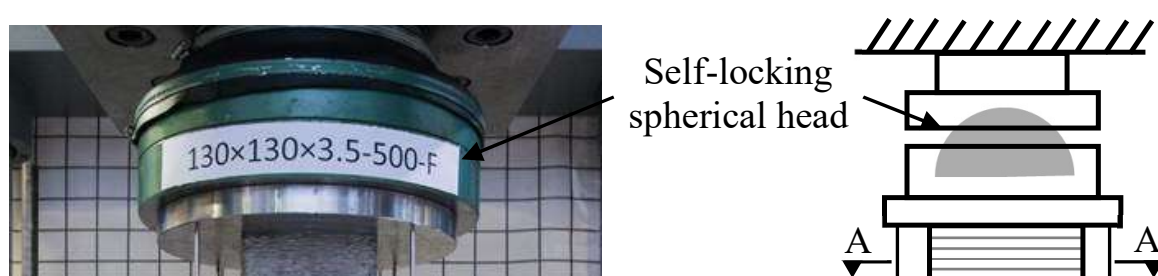

spherical head

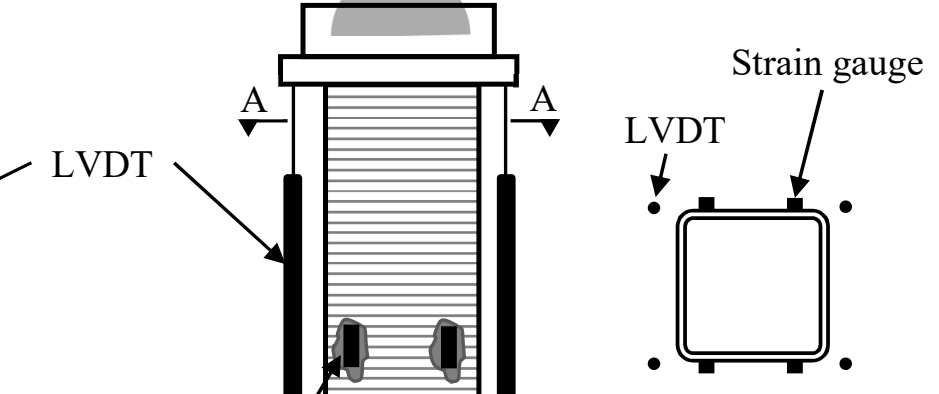

Strain gauge

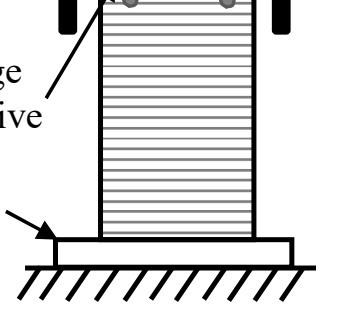

Section A-A on PS adhesive

End platen

803

Figure 21: Experimental setup for stub column tests

804

805
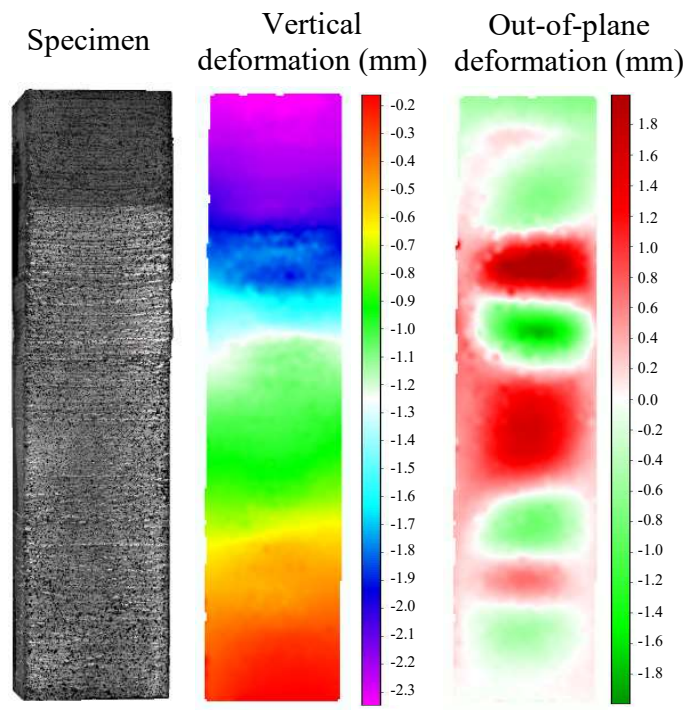

Specimen

Vertical

Out-of-plane
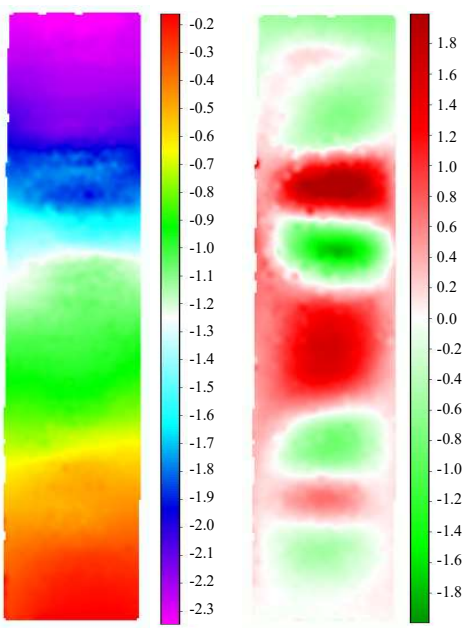

(a) WAAM SHS, $\bar{\lambda}_{\mathrm{p}}=1.13$

806

$(180 \times 180 \times 3.5-720-\mathrm{FR})$
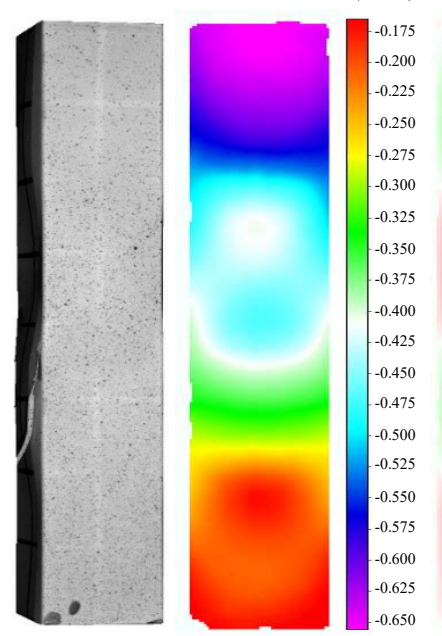

(b) PBF SHS, $\bar{\lambda}_{\mathrm{p}}=1.12$

Figure 22: DIC analysis of typical WAAM and PBF specimens at ultimate load 


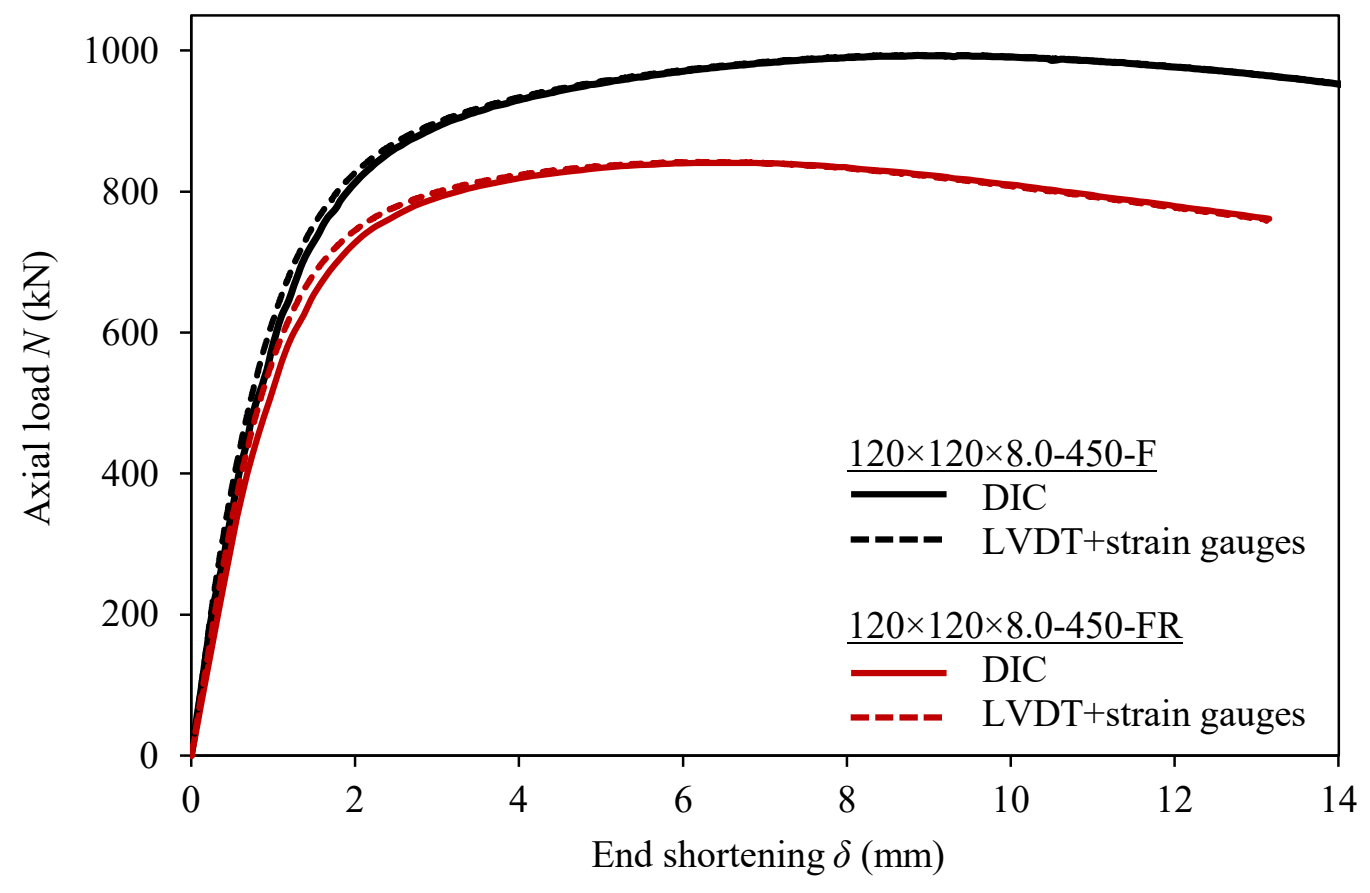

810 Figure 23: Typical comparisons of load-end shortening curves derived using DIC and LVDT+strain 811 gauge data 

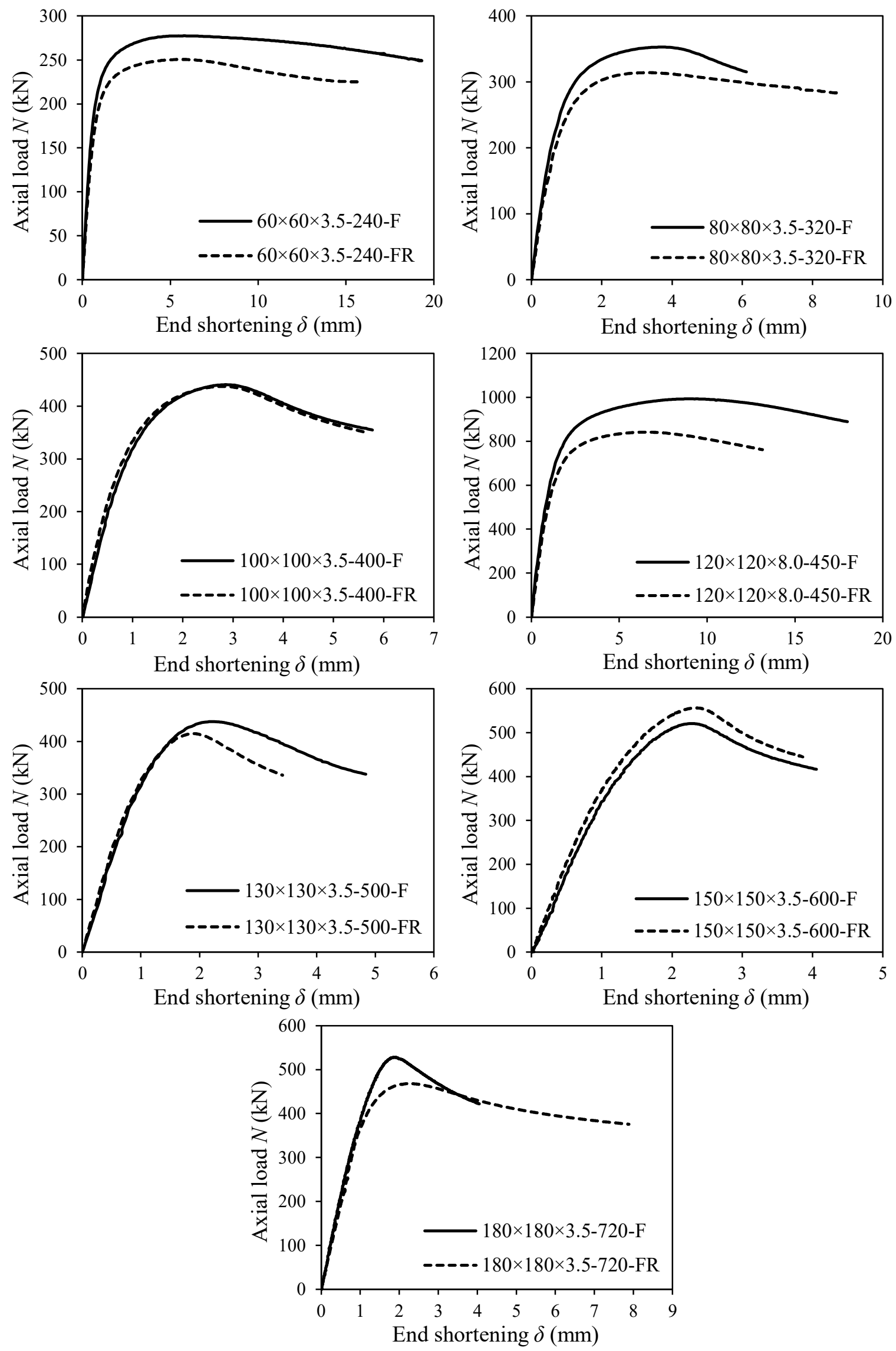

Figure 24: Load-end shortening curves of tested stub columns 

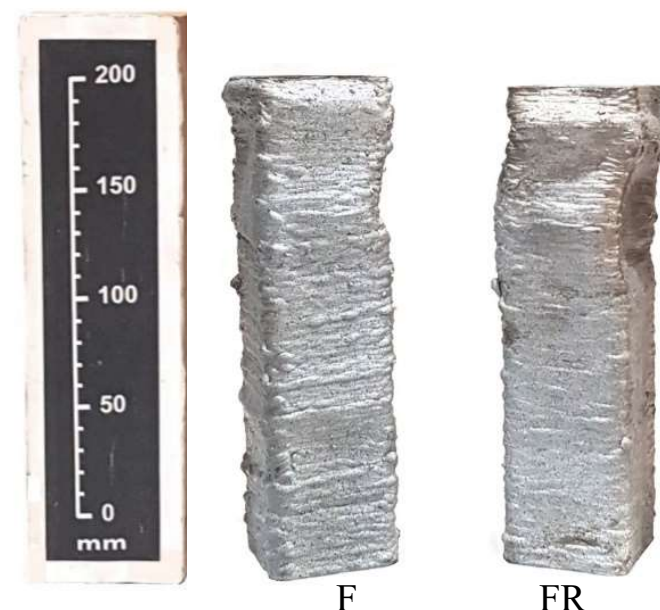

(a) $60 \times 60 \times 3.5-240$

FR

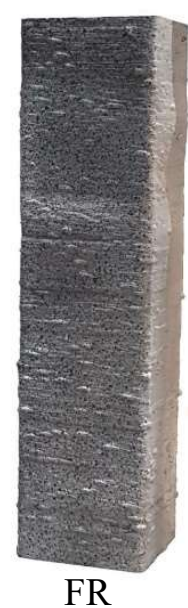

(c) $100 \times 100 \times 3.5-400$

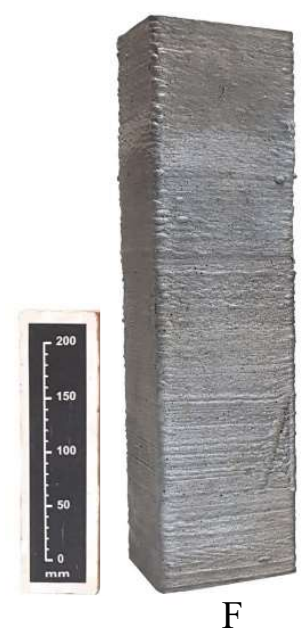

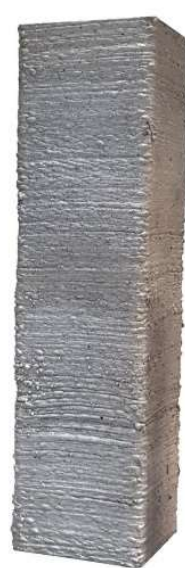

FR

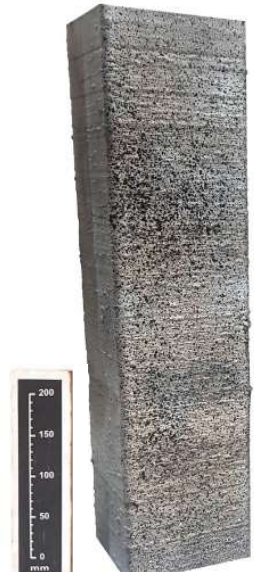

$\mathrm{F}$

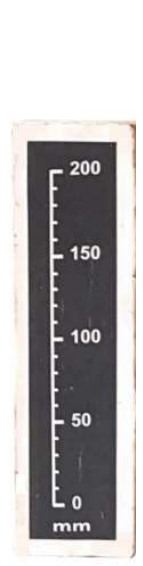

$\mathrm{F}$

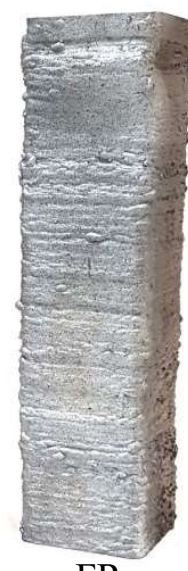

FR

(b) $80 \times 80 \times 3.5-320$
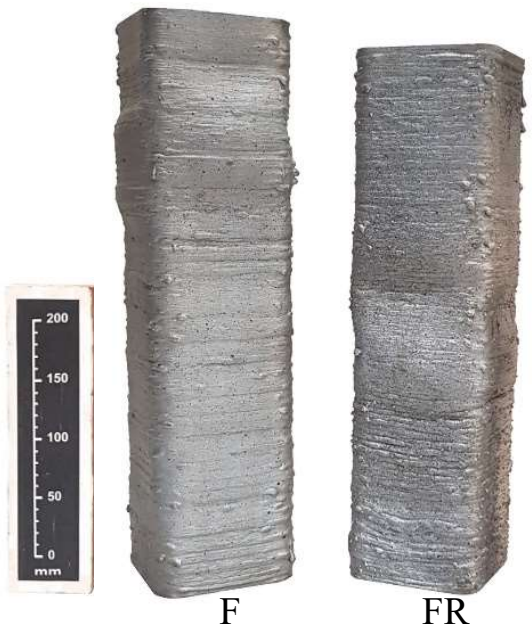

(d) $120 \times 120 \times 8.0-450$

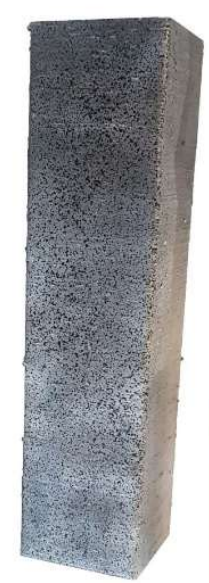

FR

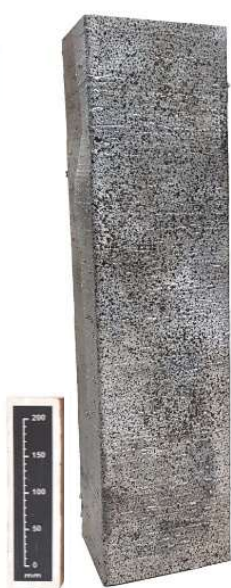

$\mathrm{F}$

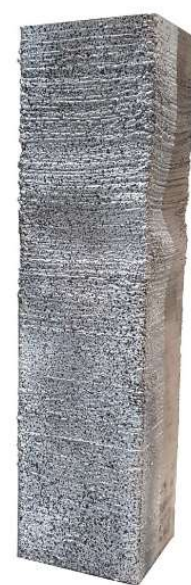

FR

(f) $150 \times 150 \times 3.5-600$

(g) $180 \times 180 \times 3.5-720$ 


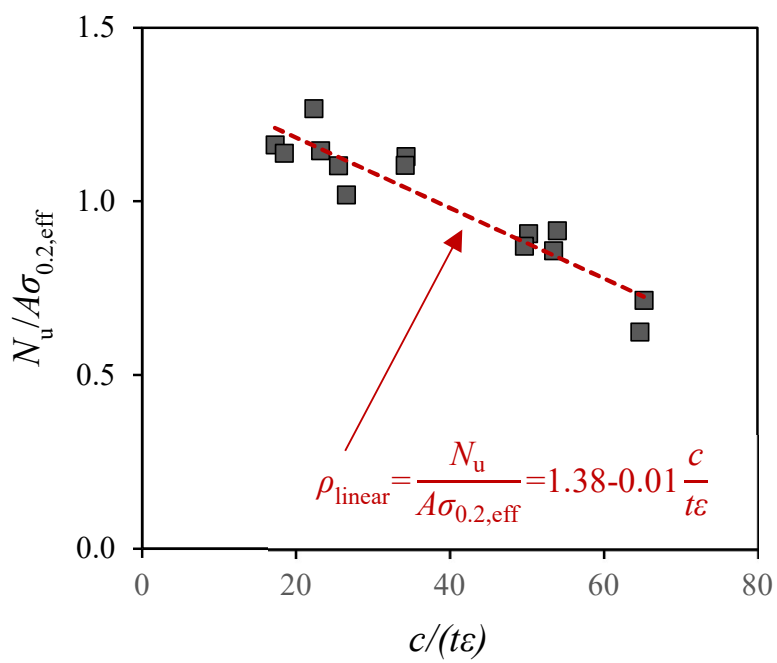

(a)

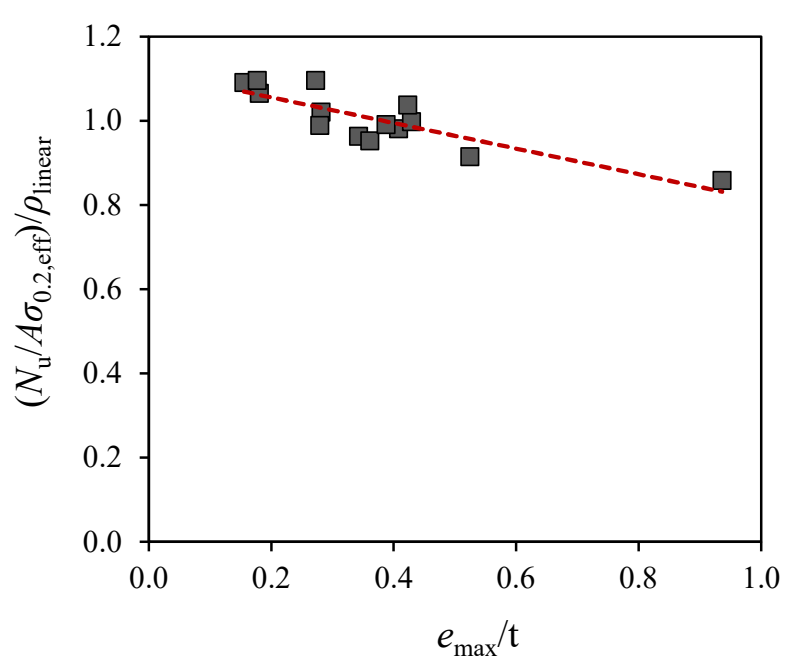

(b)
817

818

819

820

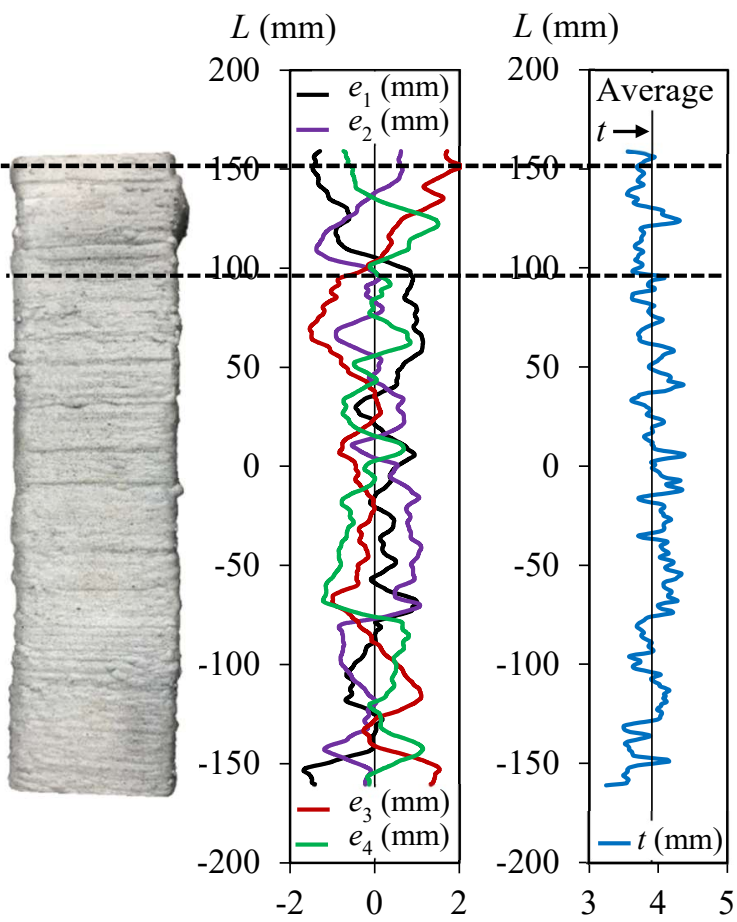

(a) Specimen $80 \times 80 \times 3.5-320-F R$

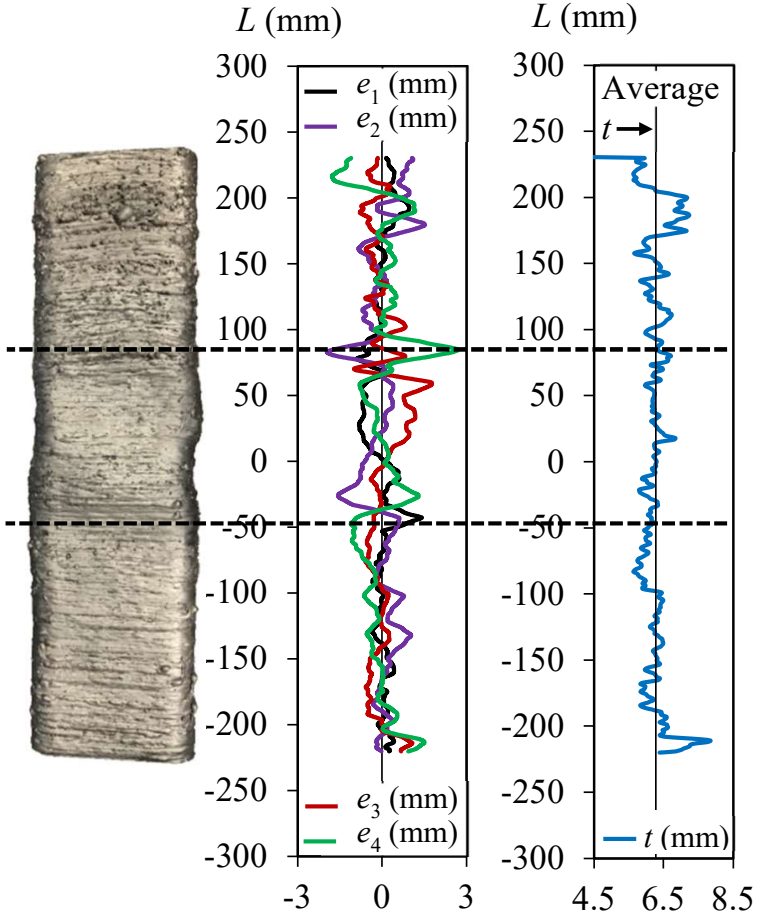

(b) Specimen $120 \times 120 \times 8.0-450-\mathrm{FR}$

Figure 26: (a) Normalized compressive capacities of specimens and (b) variation of relative response of specimens with normalized geometric imperfection amplitude

822 Figure 27: Correlation between geometric variability and failure locations for typical specimens of (a) 


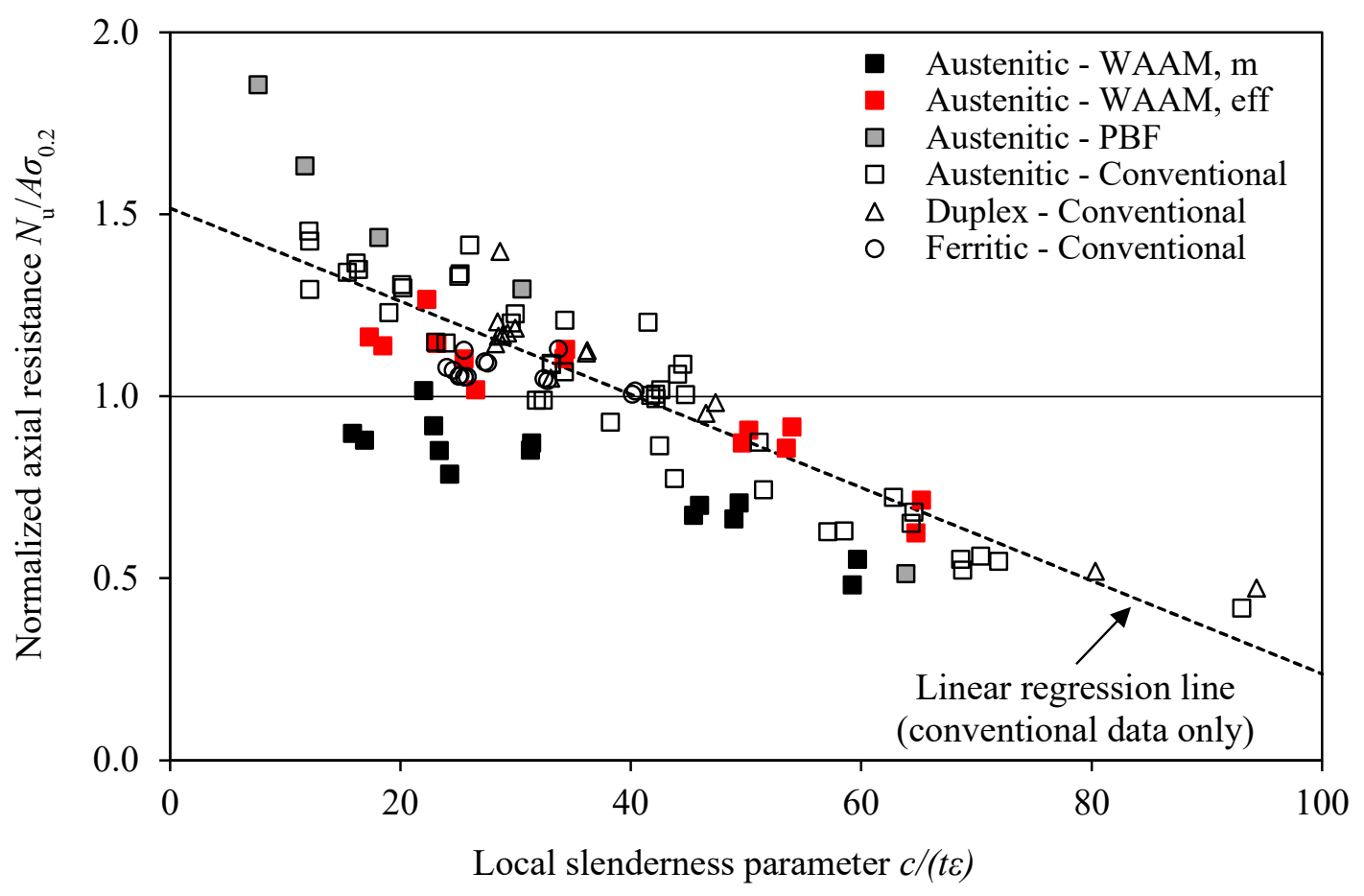

Figure 28: Comparison of normalized compressive capacities of WAAM SHS with those of PBF SHS and conventionally manufactured cold-formed SHS

827

825

826

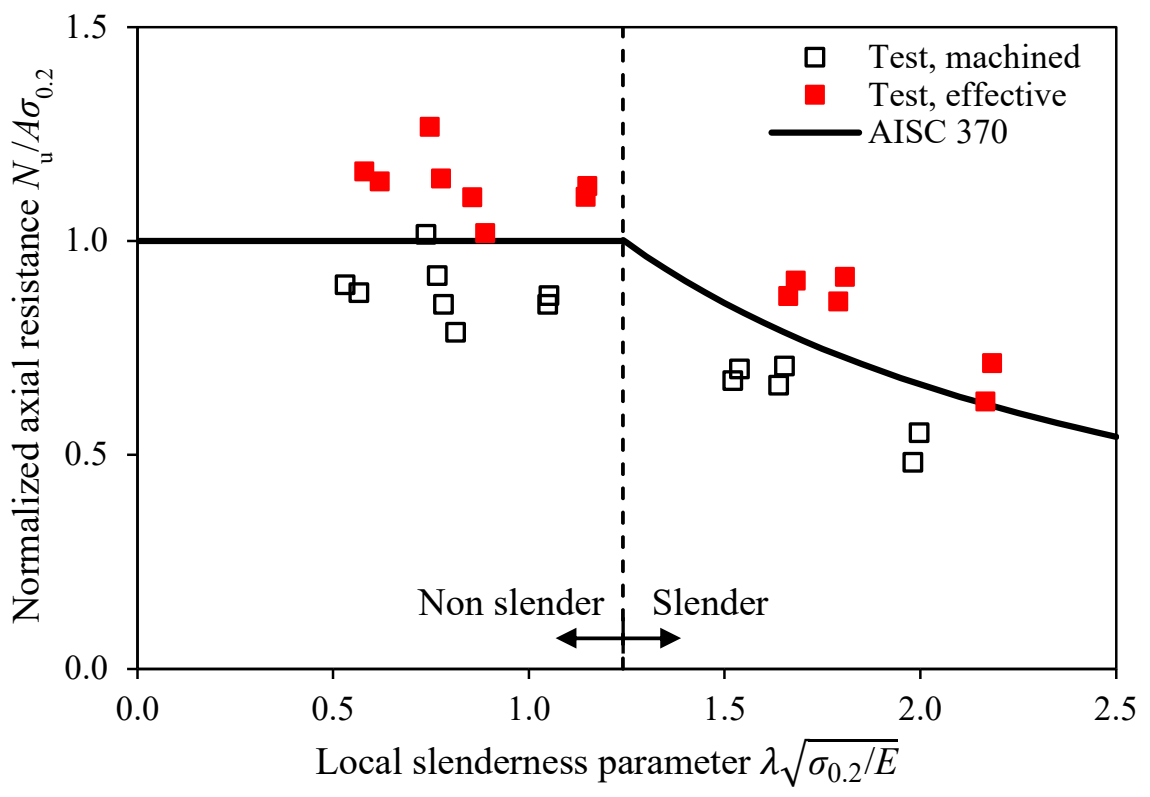

Figure 29: Comparison of compressive capacities of WAAM SHS with AISC 370 capacity predictions 


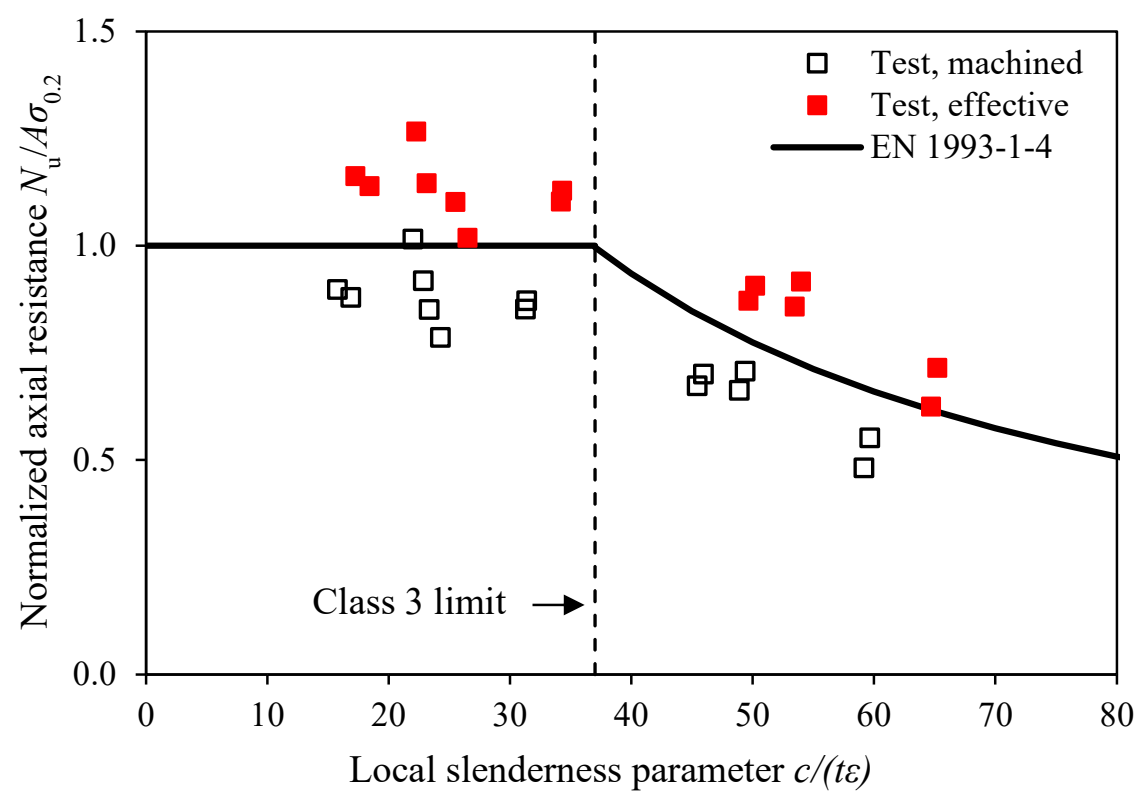

832 Figure 30: Comparison of compressive capacities of WAAM SHS with EN 1993-1-4 capacity predictions

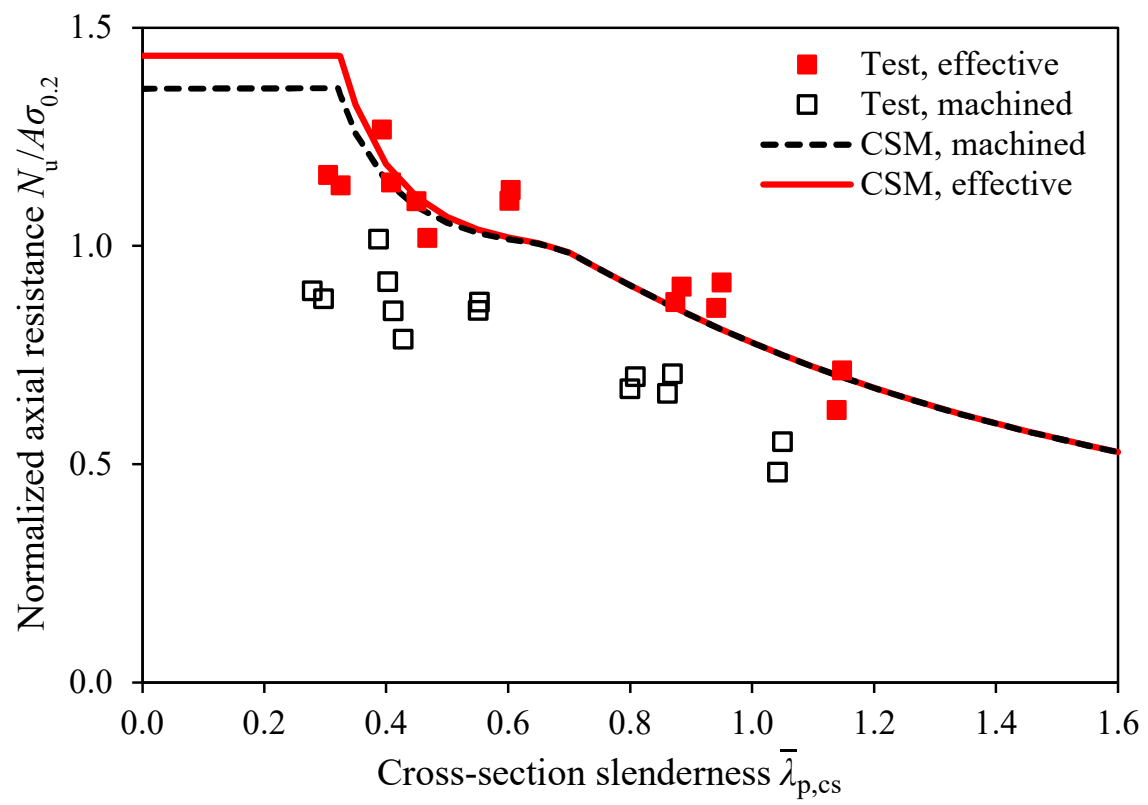

836 Figure 31: Comparison of compressive capacities of WAAM SHS with CSM capacity predictions 
840

841

842

843

844

845

846

847

848

849

850

851

852

853 